\title{
How do firms adapt? A fuzzy-set analysis of the role of cognition and capabilities in U.S. defense firms' responses to $9 / 11$
}

\author{
--- Accepted for publication at Academy of Management Journal --- \\ JEAN-PHILIPPE VERGNE* \\ Assistant professor, Ivey Business School, Western University \\ 1255 Western Road, London, Ontario, Canada N6G 0N1 \\ Email: jvergne@ivey.ca \\ Tel: +1 5196613598
}

$\&$

\section{COLETTE DEPEYRE}

Assistant professor, PSL, Université Paris-Dauphine, DRM - CNRS, UMR 7088

Place du Maréchal de Lattre de Tassigny, 75775 Paris Cedex 16, France

Email: colette.depeyre@dauphine.fr

Tel: +33 144054211

\footnotetext{
* Corresponding author. We are indebted to Philip Bromiley, Hervé Dumez, Rodolphe Durand, Peer Fiss, Frédéric Garcias, Michael Jacobides, Stefan Jonsson, Sarah Kaplan, Oliver Schilke and André Spicer for valuable comments on earlier versions. We also wish to acknowledge the helpful feedback received at conferences (AIMS 2012, AoM 2012 and 2013, SMS 2012) and research seminars (iSTOR at Ivey Business School, DRM-MOST at University Paris-Dauphine, the strategy seminar at IAE-Lille, the organization seminar at Uppsala University, the Ontario qualitative research workshop at Rotman). We gratefully acknowledge the research assistance provided by Ivey PhD student Nathan Kim, as well as the insightful feedback received from three anonymous reviewers and AMJ Associate Editor Jennifer Howard-Grenville.
} 


\title{
How do firms adapt? A fuzzy-set analysis of the role of cognition and capabilities in U.S. defense firms' responses to $9 / 11$
}

\begin{abstract}
How do firms adapt? In recent years, this old question has been given new answers—albeit partial ones. On the one hand, cognition scholars have emphasized managerial attention to environmental change as a key driver of adaptation. On the other hand, dynamic capabilities scholars have underscored the role of asset reconfigurations implemented amidst shifting environments. However, the explanatory powers of the two perspectives have not yet been assessed comparatively. We use fuzzy-set analyses of U.S. defense firms' responses to $9 / 11$ to model the two perspectives as potentially competing or complementary, but our findings suggest that neither dynamic capabilities nor superior cognition must be present for firms to adapt. Instead, we identify four types of adapters (anticipative, responsive, opportunistic, and decisive), as well as the possibility of strategic nonadaptation. These results lead us to reassess the cognition and capabilities literatures and to outline a new, integrative framework to explain adaptation.
\end{abstract}

Keywords: adaptation; cognition; attention; capabilities; asset reconfiguration; defense industry 
The primary purpose of strategic management is adaptation, i.e., to fit the firm more particularly for existence under the conditions of its changing environment.

Balaji Chakravarthy (1982: 35)

\section{INTRODUCTION}

In industries characterized by shifting conditions, strategic management is essential for firm adaptation (Burgelman, 2002; Durand, 2006; Lawrence \& Lorsch, 1967; Tripsas, 1997). Firms that manage to adapt are more likely to survive longer and perform better (Helfat \& Winter, 2011). Conversely, firms that fail to adapt are more likely to downsize, be acquired at a discount, or file for bankruptcy protection, outcomes that may trigger harmful social instability in their communities. The Detroit metropolitan area represents a well-documented case of the social havoc wreaked by the maladaptation of automobile giants Ford, Chrysler, and General Motors to the new industry conditions that emerged since the 1970s, leading to urban decay, unemployment, crime, and a fifty percent decline in population (Taylor \& Jackson, 2010).

Yet, firm adaptation over the long run, while desirable from a business and social perspective, is far from common. Burgelman and Grove (2007: 965) remind us that, "of the top 100 U.S.-based industrial companies listed in Fortune magazine in 1965, only 19 remain in the top 100 in 2005, 15 fell out of the top 100, and 66 were acquired or disbanded." Understanding the causes of firm adaptation (and lack thereof) is thus an essential mission for management scholarship, and this paper's purpose is to offer a new answer to a very old question: How do firms adapt?

Over time, scholarly efforts to explain adaptation have progressively focused on two literature streams. On the one hand, cognition scholars emphasize early managerial attention to environmental change as a key driver of adaptation (Fiol, 1990). On the other hand, dynamic capabilities scholars insist on the essential role played by asset reconfigurations implemented in response to shifting conditions in an effort to realign firm resources with market conditions (Teece 
et al., 1997). We have thus analyzed both managerial attention and asset reconfigurations in our empirical setting, namely the U.S. defense sector, around the time when the $9 / 11$ terror attacks epitomized a profound shift in the industry. Indeed, for defense firms, 9/11 crystallized a wave of technological, economic, and strategic mutations that began in the late 1990s with the so-called "revolution in military affairs" promoted by the Pentagon. The "perception of heightened external threat levels after 9/11 provided opportunities for transformation advocates" (Dombrowski \& Ross, 2008: 21), and made it clear to every major industry player that adaptation was needed for firm survival. One of the most observable changes was the Pentagon's effort at "alleviating the boundary between the military and the civilian", essentially creating "a new defense strategy" that U.S. arms contractors had to live by, as it came from their primary customer (Lasserre, 2009).

To gain a deep understanding of adaptation, we tracked 17 U.S. defense firms' trajectories before and after $9 / 11$, and found puzzling patterns of adaptation. First, some firms anticipated the changes very early on, even before 9/11 made the industry's shifting conditions an inescapable reality. For instance, as early as 1999, Northrop Grumman’s top management understood that if “a 'revolution in military affairs' bec[a]me a central tenet of U.S. defense planning, [the firm's] business focus on sensors, electronic warfare systems, space, and information technologies w[ould] reinforce [its] competitive position well into the next century" (Northrop Grumman Annual Report, 1999). However, at odds with what the cognition lens would typically predict, this early attention to change was not always followed by intense strategic renewal. Even more surprisingly-this time from a dynamic capabilities perspective_-another set of defense firms, including for example Halliburton, managed to adapt despite a delayed reaction and lower asset reconfiguration intensity after the environmental shift. On the contrary, some firms that reconfigured their assets substantially in response to the shift actually ended up, in terms of adaptation, worse off than some of their more passive competitors, as was the case for Computer Sciences Corp.: it acquired Dyncorp in 2003 but 
two years later spun off its military equipment and training businesses.

To explain these patterns, we consider the complementarities and points of intersection between the cognition and capabilities literatures by posing the following research question: In an industry experiencing an environmental shift, how do managerial attention and asset reconfiguration contribute to firm adaptation - or lack thereof? To explain overall adaptation at the firm level while identifying causal conditions, we build on a method recently introduced to the field of management (Fiss, 2009), namely, fuzzy-set qualitative comparative analysis (fsQCA). This method of analysis enables us to assess the effects on adaptation (or lack thereof) of key variables from the cognition and capabilities literatures, and to account for complex interactions between these effects (Ragin, 2008).

By shedding new light on the complex causality underpinning adaptation, our integrated framework helps to make sense of phenomena that would otherwise be difficult to explain from the viewpoint of either the cognition or dynamic capabilities literature, taken separately. Our identification of four types of adapters (anticipative, responsive, opportunistic, and decisive) demonstrates that attention and asset reconfigurations act sometimes as complements and other times as substitutes (Burgelman, 2002; Tripsas, 1997). We find superior cognition to be absent from many adaptation events, and that slowing the pace of asset renewal in response to environmental change can enhance adaptation-two results that suggest, interestingly, that neither superior cognition nor dynamic capabilities must be present for firms to adapt. In addition, our study allows us to distinguish between situations wherein top managers are not aware of the need for change (i.e., inferior cognition), and situations of strategic non-adaptation, wherein despite awareness of shifting conditions, managers gauge that change is not a priority given the firm's current revenue profile. We discuss implications of these findings for research on cognition, dynamic capabilities, and adaptation at the end of the paper. 


\section{MANAGERIAL ATTENTION, ASSET RECONFIGURATION, AND ADAPTATION}

In their early stages, the cognition and capabilities literatures have, to a large extent, evolved independently to account for similar phenomena. For instance, while both Kiesler and Sproull (1982) and Dierickx and Cool (1989) seek to explain why some organizations adapt better and survive longer, the former focus on managerial problem-sensing and the latter on unique assets and capabilities. Two early accounts, which both emphasized that adaptation can take different forms, have had a substantial influence on current scholarship. For Chakravarthy (1982), adaptation depends on how firms notice and process new environmental cues. For Hrebiniak and Joyce (1985), the two essential dimensions to consider are the extent of strategic choice and of environmental determinism. The literature on cognition (e.g., Nadkarni \& Barr, 2008) builds on Chakravarthy's account to emphasize the role of managerial attention to predict the occurrence — and nature-of firms' responses to environmental shifts (Barr, 1998; Fiol, 1990). A related stream on capabilities (Bradley \& Aldrich, 2011; Peteraf \& Reed, 2007) furthers Hrebiniak and Joyce's agenda, and examines how strategic choice, manifest in asset reconfigurations implemented in response to environmental change, affects firms' long-term adaptation to industry conditions (Moliterno \& Wiersema, 2007). Below, we briefly review these two literatures before making the case for an integrative framework.

\section{Cognition and Firm Response: The Role of Managerial Attention}

The literature on cognition connects managerial attention to environmental cues with the subsequent firm actions implemented as a response to shifting conditions. Garud and Rappa (1994) offered a seminal contribution to this literature in their study of cochlear implants, which unpacks the relationship between understandings of a technology and the strategic choice to invest in one technology over another. Subsequent studies have explicated a series of interrelated mechanisms. For example, Barr (1998) showed that, absent the awareness of new challenges posed by their 
environment, managers of a fairly performing firm feel no urgency to reconfigure their firm's assets. Eggers and Kaplan (2009) complemented this finding by establishing that managerial attention timing is important for explaining the speed of asset reconfiguration. Several scholars further demonstrated that cognition precedes asset reconfiguration- that is, managerial attention leads to strategic change, as shown in studies that seek to mitigate simultaneous and reverse causality, and rule out alternative explanations (Cho \& Hambrick, 2006; Cool \& Schendel, 1987; Kaplan, Murray, \& Henderson, 2003). At the industry level, cognition scholars found that competitors endowed with similar assets can respond very differently to the same environmental shift when their top managers' attentional patterns differ (Fiol, 1990; Osborne, Stubbart, \& Ramaprasad, 2001; Porac \& Thomas, 1994). Another major finding, from Tripsas and Gavetti's (2000) study of Polaroid's failure despite its early investment in digital imaging assets, showed that inferior cognition can lead to nonadaptation even when assets have been reconfigured to address the shifting environment.

Going forward, to gain a deeper understanding of the mechanisms underlying managerial attention, cognition research could be furthered in two complementary directions. First, cognition scholars could investigate whether adaptation and non-adaptation have symmetrical causes-for instance, can adaptation also occur in the presence of inferior cognition? As well, to look more thoroughly beyond the Attention $\rightarrow$ Reconfiguration link, this literature could examine how cognition variables (e.g., attention timing) affect the contribution of asset reconfigurations to adaptation-for instance, are several forms of adaptation underpinned by different ways of paying attention to the environment and reconfiguring assets?

\section{Firm Response and Adaptation: The Role of Asset Reconfiguration}

To understand how firms adapt, another breed of scholars has examined the different types of responses to environmental change implemented by firms, manifest in the way they reconfigured their assets (Pavlou \& El Sawy, 2011; Schilke, 2014). Rooted in the notion of "dynamic capability," 
this literature has focused on the Asset Reconfiguration $\rightarrow$ Adaptation link, and has looked at such asset reconfigurations as mergers and acquisitions (Karim \& Mitchell, 2000), divestitures (Moliterno \& Wiersema, 2007), and business unit reorganizations (Danneels, 2010). The profound influence of the resource-based view (Barney, 1991; Wernerfelt, 1984) on this research stream led to the working hypothesis that, by leveraging capabilities to reconfigure assets in a unique fashion, firms could perform certain tasks in superior ways and thereby gain an edge over competitors (Leiblein, 2011).

An interesting area of tension in this literature is in regards to how the intensity of asset reconfiguration affects adaptation. Whereas some argue that firms require substantial organizational change to address shifting environmental conditions (Teece et al., 1997), Helfat and Winter (2011) claim that firms' reconfigurations need not be massive to enhance their adaptation. If firms adapt by relying on change routines, which by definition are stable patterns of repeatable actions (Winter, 2003), then small-scale asset reconfigurations should be a common way of achieving adaptation. As well, Burgelman and Grove (2007: 966) note that "leading researchers of [...] adaptation warn about the potential dangers of change associated with exploratory activities, because while the upside of correct decisions is very high, the downside of wrong ones can 'lead to major disasters' (March, 2006: 205)." In sum, big changes happening too fast may put the entire organization at risk.

A related issue is the scope of asset reconfiguration. Especially in large firms consisting of several strategic business units (SBUs), even a substantial environmental shift may not require reconfigurations in every SBU (Danneels, 2010), as multi-business firms operate in several industry segments characterized by different conditions, and thus face distinct challenges and opportunities in terms of adaptation. However, most research examines adaptive strategies at the corporate level, as opposed to the finer-grained SBU level (an exception is Martin, 2011). Besides, research on the "autonomous process through which an organization can indefinitely remain adaptive" (Burgelman, 1991: 522) has emphasized the role of bottom-up experimentation, within SBUs, which paves the 
way for strategic renewal that is independent from close top managerial supervision. This approach further emphasizes the relevance of this intermediate level of analysis for understanding the connection between asset reconfigurations, which take place within SBUs, and the overall adaptation of firms operating in heterogeneous environments. Along these lines, Jacobides (2006) expanded the scope of investigation by examining the role of assets reconfigurations within and between firms, as driven by the integration and disintegration of various capabilities.

As per the resource-based view, clear trade-offs exist between internal reconfigurations (e.g., merging two SBUs to develop a shared technology) and external reconfigurations (e.g., acquiring a firm to access its technology). However, the literature has been mostly silent on how these trade-offs affect a firm's ability to adapt to environmental shifts (see Capron \& Mitchell, 2008, for an exception).

\section{Opportunities for Integration}

Both cognition scholars and capabilities scholars seek to explain adaptation. The cognition literature outlines a robust theory explicating the link between managerial attention and asset reconfiguration, and empirically identifies the key variables triggering firm response-most notably, managerial attention focus, intensity, and timing (Kaplan, 2011). The capabilities literature has created valuable knowledge about the various types of asset reconfigurations implemented by firms in an attempt to address environmental change (Leiblein, 2011).

However, as Eggers and Kaplan (2013: 295) put it, until recently "capabilities scholars have focused on capabilities as a source of inertia or adaptation to the environment without considering how the interpretation of the possibilities presented by the environment might matter for outcomes." Only in the past few years have capabilities scholars begun to explicitly recognize that "responding to $[\ldots]$ change in the business environment involves diagnosing the structure of any new challenges," and that "sensing $[\ldots]$, understanding opportunities $[\ldots]$ and figuring out the next 
big challenge" have become key success factors in the age of "entrepreneurial managerial capitalism" (Teece, 2012: 1397-98). At the same time, new research on cognition has started to focus on the intersection between capabilities and asset reconfigurations. Laamanen and Wallin (2009), for instance, argue that managerial attention to capability bottlenecks will shape the adaptation process, while Kaplan (2008) examines the interaction effects between cognition and firm capabilities.

This convergence suggests that the two literatures need to be treated on equal footing, and that scholars must now tease apart how cognition and capabilities jointly and interactively affect adaptation. This new approach could shed new light on several related questions at the intersection of cognition and capabilities research: Can a firm adapt when it uses capabilities to reconfigure assets but its top managers miss important environmental cues? Is there value in delaying attention to an environmental shift when the firm has the capability to reconfigure assets swiftly? Or can asset reconfigurations hurt the firm's adaptive potential when implemented suddenly after realizing that industry conditions are changing? Can adaptation and non-adaptation be explained by the same attention and reconfiguration variables?

To deepen our understanding of adaptation, we thus extend recent efforts at integrating the two perspectives (Kaplan, 2008; Eggers \& Kaplan, 2013) by looking at the entire chain of events, namely Attention $\rightarrow$ Reconfigurations $\rightarrow$ Adaptation. Our objective is to gain new insights regarding the two streams' respective contributions to adaptation.

\section{Firm Adaptation: A Controversial Outcome}

In this paper, we refer to adaptation as the extent to which a firm is congruent with its current environment. At any point in time, adaptation results from prior firm behavior-in particular managerial attention to environmental change and asset reconfigurations implemented to renew firm strategy (Burgelman \& Grove, 2007; Chakravarthy, 1982; Gould, 2002). Indeed, in a shifting environment, managers need to focus their attention on the external cues that indicate how the 
industry is changing (Barr, 1998), and then leverage their firm's capabilities in an effort to reconfigure the firm assets accordingly (Ambrosini, Bowman, \& Collier, 2009).

Despite these early insights, empirical research on firm adaptation has not been thriving in recent years. In fact, some argue that the adaptation literature is plagued by a number of conceptual and methodological issues (Arend and Bromiley, 2009; Durand, 2006; Priem and Butler, 2001; Zahra et al., 2006) that need to be fixed if the adaptation research agenda is to move forward. For example, though "achiev[ing] congruence with the changing business environment" (Teece et al., 1997: 515) is presented as the essential outcome of dynamic capabilities, many empirical studies in this tradition use a measure of performance (instead of "congruence") as their dependent variable (e.g., Adner and Helfat, 2003; D'Este, 2002; Drnevich and Kriauciunas, 2011; Pavlou and El Sawi, 2011), potentially leading to tautological arguments. Cognition research, on the other hand, has not attempted to capture adaptation at the firm level, and instead examines intermediate outcomes (e.g., market entry, as in Eggers and Kaplan, 2009) without assessing their impact on overall adaptation. We have strived to address the limitations flagged in prior critiques to craft a new research design that will hopefully move forward the adaptation research agenda, both conceptually and methodologically. Table 1 below lists seven issues identified in the literature, and explains how this study addresses them. Details on the methodological implications can be found below.

--- Insert Table 1 about here ---

\section{METHODS AND EMPIRICAL ANALYSIS}

\section{Overview of the Method}

Fuzzy-set qualitative comparative analysis (fsQCA) is a "novel methodology for modeling causal relations $[\ldots]$, based on the idea that causal relations are frequently better understood in terms of set-theoretic relations rather than correlations" (Fiss, 2011: 395; Ragin, 2008). Although this method has only recently been introduced to management scholarship (Fiss, 2007, 2009), it has 
already produced useful results that refine, deepen, extend, and integrate existing theories (Crilly, Zollo, \& Hansen, 2012; Fiss, 2011; Misangyi \& Acharya, 2014). FsQCA is well-suited to analyze relationships between different types of causal conditions (here, cognition- and capabilities-related causes) in situations "where single conditions do not display their effect of their own, but only together with other conditions," a phenomenon known as "conjunctural causation" (Durand \& Vaara, 2009; Schneider \& Wagemann, 2012: 6). FsQCA relies on logical minimization to identify necessary and sufficient conditions that predict the occurrence and non-occurrence of an outcome (here, adaptation and non-adaptation). Necessary conditions are causes that must be present for an outcome to occur (e.g., without flour, no bread can be made; thus, flour is a necessary condition for bread). Sufficient conditions are causes that always lead to the outcome (e.g., putting dough in a gas oven will always raise the dough's temperature; thus, a gas oven is a sufficient condition for baking dough). ${ }^{1}$

To identify these conditions, fsQCA seeks commonalities and differences across cases sharing the same outcome. For example, after observing that all breads contain flour, one could infer that flour is a necessary condition for bread-or put differently, that bread is a subset of "things that contain flour." Sufficient conditions are identified using a truth table algorithm, available in a dedicated software package that "maps the logically possible and empirically occurring combinations of fuzzy sets under study" (Misangyi \& Acharya, 2014: 1692) against membership scores in the outcome set. For example, while it is logically possible to have a 21 -year-old CEO running a topperforming S\&P 500 firm, this situation may remain unobserved empirically, in which case the intersection between the outcome set "being a top-performing S\&P 500 firm" and the causal condition "having a very young CEO" is an empty set. In that sense, findings obtained with fsQCA

\footnotetext{
${ }^{1}$ However, flour is not a sufficient condition for bread (i.e., salt, water, and yeast are also needed); specialties other than bread can be made with flour; and a gas oven is not a necessary condition for baking dough (i.e., frying pans and an open fire can also be used).
} 
are more conservative than results of regression analyses since, unlike the latter, they do not allow for out-of-sample predictions.

Our use of fsQCA leads to cases (here, firms) being conceived of as combinations of theoretically relevant properties (pertaining to cognition and capabilities) that are causally linked to an outcome of interest (adaptation or non-adaptation). Extant theory is used to guide data collection and calibrate set membership between 0 (full non-membership in a fuzzy set) and 1 (full membership), with 0.5 representing a qualitative anchor that signals maximum ambiguity regarding membership (Greckhamer, Misangyi, Elms, \& Lacey, 2007). Importantly, in fsQCA, sets simultaneously capture both qualitative and quantitative differences. $^{2}$

FsQCA has several advantages in the context of this study. First, it will allow us to identify separately the antecedents of adaptation and of non-adaptation. ${ }^{3}$ Second, fsQCA enables an integration of two related literatures by examining complementarities among their core variables, all within a causal framework that does not neglect the qualitative insights obtained from the case studies. Crilly et al. (2012), for instance, combined insights from decoupling theory and stakeholder theory to explain firm responses to institutional pressures. In this paper, we examine managerial attention and asset reconfiguration to cross-fertilize the cognition and capabilities literatures.

\section{Seventeen U.S. Defense Firms Facing 9/11}

Using qualitative and quantitative data, we analyze the influence of managerial attention (i.e., the key construct in cognition research) and asset reconfiguration (i.e., the observable outcome of using capabilities) on defense firms' adaptation to a shift in their industry, as crystallized by 9/11.

Industry context. In the 1990s, a progressive rethinking of U.S. military strategy resulted

\footnotetext{
${ }^{2}$ This concept is much like the $0^{\circ}$ Celsius anchor in temperature measurement. A quantitative temperature increase of only one degree is needed to reach $+1^{\circ} \mathrm{C}$, but that one degree also changes the physical state of water qualitatively, from solid to liquid. Thus, within one single scale, both qualitative and quantitative differences are captured.

${ }^{3}$ Econometrics cannot easily model causal asymmetry since "correlations are by their very nature symmetric; for example, if one models the inverse of high performance, then the results of a correlational analysis are unchanged except for the sign of the coefficients" (Fiss, 2011: 394).
} 
from the fall of the Soviet bloc, the rise of asymmetric threats, and the emergence of smaller conflicts. The environmental shift under study has its roots in the late 1990s, when Pentagon reports began to mention such new concepts as "full-spectrum dominance" (U.S. Joint Chiefs of Staff, 1996), "integrated system of systems” (U.S. Department of Defense, 1997), “cyberspace revolution,” and "network-centric warfare" (NCW; Cebrowksi \& Garstka, 1998). A common thread across the reports was that weapon systems as scalable swarms needed to be smaller, lighter, and faster. Complexity was to be transferred from the nodes (e.g., battleships) to the network, but the implications for U.S. defense firms remained unclear.

Then, 9/11 gave substance to the new threats that the U.S. had begun to foresee, and shed light on several gaps in U.S. defense capabilities. Both the Quadrennial Defense Review Report and the Network Centric Warfare Report to Congress (U.S. Department of Defense, 2001a, 2001b) provided clearer guidelines for accelerating the transformation of the U.S. military. U.S. defense spending had decreased by more than 50\% over the 1990-2000 period but had started to increase again in 2001, and continued to grow steadily afterwards (+49\% over 2001-2005).

Although ideas related to the "revolution in military affairs" emerged slightly before 2001, 9/11 represented an exogenous shock that suddenly made military transformation highly salient to all industry players. Before $9 / 11$, defense firms could only pick on weak signals and try to anticipate, at least partly, some of the changes discussed in the Pentagon reports. So, by the time of the 9/11 attacks, U.S. defense firms differed in their degree of preparedness (captured below by our attention variables). After $9 / 11$, the environmental shift became an inescapable feature of the defense industry.

As noted by one of the experts we interviewed during the preliminary phase of this study, the shift was not only about technology, and "the first NCW contract allocations surprised many industry stakeholders." For instance, in 2002, Boeing secured the first U.S. Army NCW contract for "Future Combat Systems." A substantial share of this contract concerned ground vehicles, despite 
Boeing having never previously manufactured such vehicles. U.S. defense firms, more than ever before, were now competing for Pentagon contracts across the entire spectrum of defense systems (sea, land, and air), and past contract awards became increasingly poor predictors of future contracts (Depeyre \& Dumez, 2009).

Observation period. We chose 1998 as the start of our observation window because it represents a pivotal year, marking the end of post-Cold War transition with the cancellation of the planned merger between Lockheed Martin and Northrop Grumman. We chose 2005 as the end of our window to observe firm adaptation to the post-9/11 conditions unfolding over time, with the Afghan and Iraqi wars taking place in the background. Our temporal bracketing (Langley, 1999) thus includes both the four-year period leading to $9 / 11$ and the four-year period following the attacks.

Case selection. FsQCA can combine robust causal analysis and in-depth qualitative knowledge of the cases at hand. To achieve the former without missing the latter, scholars recommend analyzing between 10 and 50 cases (Ragin, 2008). We selected firms based in the U.S., the world's largest defense market and the one most directly affected by $9 / 11$. Using the Defense News and SIPRI rankings of top defense contractors, we identified publicly traded firms whose defense revenues above $\$ 1$ billion represented at least 5\% of total revenues (Defense News, 19982007; SIPRI, 2006). We ended up with 17 firms that produce weapon systems such as bombers, armored vehicles, missiles, and defense electronics. ${ }^{4}$ Their full names are displayed in Table 2 below.

\section{Overview of Data Sources}

To gain a deep knowledge of the industry and to better understand the environmental shift at stake, we used mixed methods. First, we reviewed government reports, memos written by defense

\footnotetext{
${ }^{4}$ We excluded two firms with missing data (e.g., Navistar) and four firms acquired early in our observation period (e.g., Newport News Shipbuilding, in 2001) to ensure comparability before and after 9/11. Note that our sample is not meant to be representative of the U.S. defense industry in general (e.g., we exclude small, low-tier contractors). Instead, we focus on firms likely both to be affected by the environmental shift and to respond to it in different ways. This is not an issue since "fsQCA does not rest on an assumption that data are drawn from a given probability distribution [and] set membership is defined relative to substantive knowledge rather than the sample mean, thus further reducing the importance of sample representativeness" (Fiss, 2011: 402).
} 
experts, and books authored by defense economists. Second, both authors gained access to industry experts via snowball sampling and conducted 17 preliminary interviews with expert analysts (6), defense scholars (3), defense procurement officials (2), and company executives (6). ${ }^{5}$ The interviews focused on the transformation of the industry since the end of the Cold War and in the aftermath of 9/11. Interview topics included procurement, systems integration, strategic challenges, and market regulation. These interviews were designed to gain a broad understanding of the industry, and were helpful for outlining some of this study's central concepts (e.g. environmental shift). Third, we collected commentaries on corporate activity in business newspapers and specialized defense media, such as Defense Daily, Jane's Defence, and Defense News, to clarify, confirm, and triangulate our data.

Fourth, we collected yearly firm-level data. We identified several sources consistently available over the period 1998 to 2005 to capture managerial attention and asset reconfiguration. An important source consists of 137 Letters to Shareholders (LtS), which introduce the firms' annual reports. ${ }^{6}$ We complemented the dataset with comments by the chief executive officers (CEOs) in news releases, media interviews, and conference calls with analysts. We also gathered extensive data on asset reconfigurations between 1998 and 2005 from annual reports, industry reviews compiled by defense analysts, and two specialized databases-Mergent Database and Infobase-the latter, a leading provider of competitive intelligence for defense professionals. Finally, to capture firm adaptation, we designed an online survey that we sent to international defense industry experts.

\section{Definition and Calibration of the Outcome: Firm Adaptation}

Measuring firm adaptation in general is a challenging task. Arguably, an easier task is measuring

\footnotetext{
${ }^{5}$ Most respondents refused to be recorded and requested anonymity. The semi-structured interviews were conducted in Sweden, France, and the United States between 2006 and 2008.

${ }^{6}$ Eight LtS were collected for each of the firms (1998-2005), except for LLL (which had no LtS in 1998; instead, we used an IPO prospectus with similar content) and UNI (for which no LtS were found for 1999 and 2001-03; instead, for 2001, we used the "Management's discussion and analysis" section of the annual report, and computed averages for our measures over the 1998-2000 and 2002-2005 periods based on available years). For six firms (ATK, CSC, DRS, HAR, ROC, and URS), 2006 annual reports were also added to allow for yearly comparisons, i.e., we made adjustments to account for differences in publication dates.
} 
firm adaptation to a clearly defined environmental shift (see Issue 3 in Table 1). However, when studying multiple cases in retrospect, scholars must be cautious to not reverse the causality between adaptation and survival (e.g., Firm X did not go bankrupt following the shift; therefore, it must have adapted successfully). None of the firms in our final sample went bankrupt between 1998 and $2005{ }^{7}$ Besides, to avoid conflating adaptation with performance (see Issue 2 in Table 1), we designed a survey-based measure of adaptation that does not rely on performance indicators (e.g. return on assets; but see Appendix 3. B-C for robustness analyses).

We leveraged our industry knowledge and reached out to internationally recognized defense experts after designing a simple survey wherein we asked: "In your opinion, to what extent did the following U.S. defense firms adapt their business operations and products to the post-9/11 industry conditions as reshaped, for instance, by the Pentagon?" Possible answers ranged from 1 ("adapted very poorly to post-9/11 conditions") to 7 ("excelled at adapting to post-9/11 conditions"). For the midpoint, 4, the survey indicated "adaptation to post-9/11 conditions in industry average." The survey indicated that the relevant period to evaluate firm adaptation was 2002 to 2005, and that events after 2005 should not be taken into account in the respondent's answer.

We contacted ten experts who met three criteria. First, to ensure that they were already active observers of defense firms during our period of study (1998-2005), they required at least 12 years of defense industry experience. Based on publicly available biographies, we estimated the average experience of the experts we contacted to be 19 years. Second, they needed to be outsiders to the 17 firms sampled in our study. In fact, more than half of the experts we contacted were researchers or industry analysts working at high-reputation research institutes with a focus on defense, such as the Stockholm International Peace Research Institute (SIPRI), the world's leading information source on the arms trade and arms transfers. Others were defense industry analysts at consulting firms or

\footnotetext{
${ }^{7}$ As of 2014 , only three firms no longer operated as independent entities.
} 
financial institutions. All experts have published highly regarded articles, books, policy briefs, and analyses on the defense industry. Third, they needed to be able to answer the question mentioned above for each of the 17 firms. $^{8}$ In total, five experts completed the survey (response rate $=50 \%$ ).

The phrasing of the survey question remained deliberately general, in line with prior measures whose validity has been firmly established (e.g., Schilke, 2014). The respondents thus needed to rely both on their deep, tacit knowledge of how 9/11 changed the industry and, in this context, on their own understanding of what it meant for a firm "to adapt." 'The phrasing of the survey question implicitly used the entire U.S. defense industry as a benchmark, not just the 17 firms in our sample. We told the respondents that they were not expected to look for outside information when completing the survey (e.g., online search) and should rely exclusively on their own expertise.

On average, the experts gave a score of 4.7 to the 17 firms, placing them above industry average in terms of adaptation (the 4 in our scale). This is not surprising since the sampled firms are among the larger and better established players in the industry. In 10 out of 17 cases (59\%), expert scores were all either below or above the scale's midpoint (4), which, in the language of fsQCA, indicates full agreement in terms of set membership. For six out of the remaining seven cases, scores were distributed closely around their mean (e.g., TEX scored two 3s, two 4s, and one 5).

Adaptation, in evolutionary theories of management, must be assessed relative to competitors (Durand, 2006; Helfat et al., 2007). For example, if a given firm adapts well but all other firms adapt better, then the focal firm is at a disadvantage. Consistent with extant theory, we calibrated firm

\footnotetext{
8 We deliberately did not include the option "I don't know." When an expert was insufficiently knowledgeable about one or more of the 17 firms, we asked that person not to answer the survey at all (which happened twice). Our choice to privilege comparability across survey answers over maximizing the response rate was driven by our methodological commitment to fuzzy-set qualitative comparative analysis, which presupposes information symmetry and consistency of measurement across cases. As well, since we reached out to only the world's top experts in the field, we were not worried that an uninformed respondent's opinion would create noise in our data.

${ }^{9}$ Given the multiplicity of conceptual definitions for "adaptation" in management, leaving industry experts to apply their own frames to assess firm adaptation was a better strategy than imposing an abstract definition through the survey (e.g., defining adaptation in terms of "evolutionary fitness"). None of the respondents asked for clarification regarding either the meaning of the term "adapt" or the nature of "the post-9/11 industry conditions" mentioned in the survey question, which we regarded as a confirmation that these terms readily resonated with their expertise.
} 
adaptation using 4 as an anchor for the crossover membership point of 0.5 . From there, we calculated deviation scores for each firm using averages across the five experts to obtain a calibrated measure ranging between 0 and 1. Firms that are more inside than outside the set of "adapters" have membership scores above 0.5, as indicated in Table 2's last column, "Firm Adaptation." Conversely, "non-adapters" have scores below 0.5 .

--- Insert Table 2 about here ---

\section{Definition and Calibration of Causal Conditions}

Managerial attention. Following initial work by Bowman (1982), many scholars have settled on the use of Letters to Shareholders (LtS) to capture managerial attention longitudinally (for thorough justifications of this choice, see Abrahamson \& Hambrick, 1997; Barr, 1998; Barr, Stimpert, \& Huff, 1992; Cho \& Hambrick, 2006; Clapham \& Schwenk, 1991; Fiol, 1995; Kaplan, 2008; Kaplan et al., 2003; Nadkarni \& Barr, 2008). In line with best practices, we also used LtS.

We capture two dimensions of cognition deemed essential in prior research: managerial attention timing and attention intensity. To that end, both authors first read together a few letters to align the coding procedures (e.g., we decided that coded units should not be stand-alone words but meaningful text fragments), then independently coded all the fragments referring to the environmental shift using NVivo 9. We identified recurrent key terms describing the shift (e.g., "revolution in military affairs," "systems of systems," "network-centric warfare," and "cyberspace”) and used them to double-check that no relevant text fragment was omitted. This process also enhanced the comparability of our coding scheme across firms and over time. Following a wellvalidated procedure (e.g., Duriau, Reger, \& Pfarrer, 2007), we captured attention by calculating the proportion of text devoted to the shifting environment in individual $\mathrm{LtS}^{10}$

\footnotetext{
${ }^{10}$ Using proportions enabled us to control for heterogeneity in letter length and to observe the relative amount of attention devoted to various topics. Agreement between coders was high $(>90 \%)$, and the remaining ambiguities were resolved through discussion. In six
} 
In a nutshell, attention timing captures, within firms, the distribution of managerial attention to the shift over the observation period, whereas attention intensity accounts for between-firm differences in attention levels. Values above 0.5 indicate superior cognition, that is, earlier attention to the shift (for timing) and more intense attention to the shift (for intensity). More details about the calibration can be found in Appendix 1, while the fully calibrated sets can be found in Table 2 above.

Asset reconfiguration. In our review of the literature, we identified a recurrent criticism of prior measures of asset reconfigurations - the fact that firms reconfigure assets continuously, and not just to address specific environmental shifts (e.g., since 2004, Google has acquired roughly one firm each month). Because each firm is characterized by a unique baseline rate of renewal, not every asset reconfiguration can be attributed to the wish to adapt in response to an environmental shift (see Issue 7 in Table 1 above). To address this criticism, our measures follow a simple principle: we capture the within-firm increase (or decrease) in reconfiguration scope and reconfiguration intensity by subtracting the average value for the period 1998-2001 from the 2002-2005 value. By computing differences between the post- and pre-9/11 periods, we essentially control for each firm's baseline rate of asset reconfiguration in the absence of a substantial environmental shift. As a result, we can more confidently attribute observed differences to the existence of a firm's response.

We chose to capture reconfiguration scope and reconfiguration intensity because they were deemed to be theoretically important by previous studies (e.g., Danneels, 2002; Kaplan, 2008; Karim and Mitchell, 2000; also, see Issue 5 in Table 1). First, asset reconfiguration scope captures the variation, between the periods before and after 9/11, in the proportion of SBUs affected by asset reconfigurations within the firm. For each SBU, we looked at, and used as an indicator, all the asset reconfigurations driven by acquisitions and divestitures. Scores above (below) 0.5 indicate an increase

cases where the fiscal and calendar years did not coincide, we used weighted averages based on months of overlap (e.g., for a fiscal year closing on 30 April, we take 4/12th of the current LtS and 8/12th of the subsequent one to account for May-December). 
(decrease), after $9 / 11$, in the scope of asset reconfigurations, meaning that a larger (smaller) proportion of SBUs within the firm are affected by reconfigurations. Second, asset reconfiguration intensity captures a variation, between the periods before and after $9 / 11$, in the balance between major and minor asset reconfigurations, using the size of the acquired and divested businesses as an indicator of intensity. When, relative to the pre-9/11 period, a firm relied more (less) on major vs. minor reconfigurations after 9/11, reconfiguration intensity was assigned a score above (below) 0.5. Specific values for both asset reconfiguration indicators were calibrated from the 0.5 anchor using deviation scores (Schneider \& Wagemann, 2012). Details on the calibration appear in Appendix 2.

Resource dependence. A limitation of prior works on adaptation is the lack of recognition of counterfactuals such as "Firm $\mathrm{X}$ has the capability to reconfigure assets to adapt to a shifting environment yet does not exercise that capability" (e.g., for some reason, management decides not to; see Issue 6 in Table 1 above). As a result, attention to shifting conditions may or may not lead to asset reconfigurations. To capture this possibility, we build on resource dependence arguments (Pfeffer \& Salancik, 1978), according to which a firm with low dependence on a particular industry segment (e.g., in terms of revenue generation) may not prioritize change in that segment. In our context, diversified firms whose revenues do not primarily come from defense sales are, by design, less dependent on the Pentagon, which may affect their willingness to adapt after 9/11. Specifically, the Pentagon exercises less power on defense contractors whose reliance on Pentagon funding represents a minority of their revenues; thus, those defense contractors can potentially maintain their autonomy without yielding to the Pentagon's constraining demands (Wry, Cobb, \& Aldrich, 2013).

Thus, in our models, we added defense dependence as a (contextual) causal condition that represents the mean share of firms' revenue from defense in the period preceding 9/11 (1998-2001). An interesting characteristic of our sample is that no firm has defense sales in the $40-65 \%$ rangethat is, a clear gap exists around the 0.5 qualitative anchor regarding resource dependence. 
Calibrating the variable is thus straightforward, enabling us to simply use the raw measure of defense sales proportion (see Table 2). In our sample, this causal condition captures parsimoniously both an important mechanism overlooked in prior adaptation studies and a source of firm heterogeneity.

\section{FINDINGS}

We conducted four distinct sets of analyses to identify the necessary and sufficient conditions for adaptation and for non-adaptation (see Issue 4 in Table 1), using the freely downloadable fsQCA software (Ragin \& Davey, 2014, version 2.5). Table 2 contains the complete calibrated dataset, so all of our results can be easily replicated using the software. We assessed the validity of the solutions using two key metrics, consistency and coverage, that range between 0 and 1 . Consistency indicates the extent to which firms with high membership in a given solution set exhibit similar properties (i.e., consistency can be seen as a measure of a solution's internal validity). Coverage indicates the proportion of firm outcomes explained by a given solution set (e.g., a coverage score of 1 would mean the solution explains all the cases; by analogy, coverage is not unlike an R-Square statistic in regression analysis). In line with best practices, we used thresholds of 0.90 for consistency of necessary conditions, and of 0.80 for "raw" consistency and 0.75 for "proportional reduction in inconsistency" of sufficient conditions (Ragin, 2008; see also Misangyi \& Acharya, 2014: 1692). ${ }^{11}$

\section{Necessary and Sufficient Conditions for Adaptation and Non-Adaptation}

Necessary conditions for adaptation would be properties possessed by all adapters (i.e., firms with adaptation $>0.5$. We did not find any necessary condition with an acceptable consistency level (i.e., consistency scores ranged between 0.36 and 0.78 , far below the 0.90 threshold). However, we did identify two necessary conditions for non-adaptation with acceptable consistency scores: the

\footnotetext{
${ }^{11}$ In fsQCA, the researcher is encouraged to make assumptions, based on prior knowledge, to simplify the representation of logical solutions derived from the truth table algorithm. In line with resource dependence arguments, we assumed that higher dependence on defense sales would typically favor adaptation to new conditions in the defense sector. Given our goal to contrast and integrate two literatures, we decided to not make any directional assumption about any of the attention or reconfiguration variables. However, assuming that these variables contribute to adaptation does not affect our results, as demonstrated by a robustness test (unreported).
} 
absence of defense dependence (0.89) and of attention timing (0.875). In our data, all non-adapters (adaptation $<0.5)$ indeed have low dependence on defense sales (defense dependence $<0.2$ across nonadapters; see Table 2) and are fully outside the set of firms whose top managers paid early attention to the shift (attention timing $=0$ for all non-adapters). No condition related to asset reconfigurations is common among all non-adapters.

We also found four sufficient configurations of conditions leading to adaptation (i.e., when one of the four configurations of conditions is present, the firm is always an adapter). Each configuration can be seen as one of four alternative (and equifinal) paths leading to firm adaptation. Besides, we found one configuration of causal conditions leading to non-adaptation, which explains three out of four cases of non-adaptation in our sample (HON, TEX, CSC). Table 3 displays the solution, using standard notation and formatting (Fiss, 2011; Ragin \& Fiss, 2009).

--- Insert Table 3 about here ---

For instance, C1 illustrates that one option for defense specialists to adapt is to pay intense and early attention to the changing environment, and to shift the balance of their asset reconfigurations toward smaller-scale reorganizations, acquisitions, and divestitures in response to changing conditions. GEN, NOR, and ATK are three firms that took this path to adaptation.

\section{Four Types of Adapters and One Type of Non-Adapters}

To facilitate the reading of Table 3, we have labeled each configuration, and to illustrate our results further, for each of the five configurations listed in Table 3, we selected one representative firm and created a visual map displaying patterns of managerial attention and asset reconfiguration over time. The maps are based on a simple principle: the greater the intensity and scope of asset reconfigurations, the more visually dense the map. The maps are not meant to provide redundant information (e.g., data already present in Table 3 or in the paragraphs below) but to instead provide more context and richer information about firm trajectories between 1998 and 2005. 
--- Insert Figure 1 about here (Legend and 1. a to 1.e) ---

Anticipative firms (C1) are the only adapters to exhibit both intense and early attention to shifting conditions, and to not systematically increase their reconfiguration scope after $9 / 11$. In fact, these firms also decreased their reconfiguration intensity after $9 / 11$, suggesting that early and intense managerial attention can act as a substitute for asset reconfigurations. Anticipative adapters had, in fact, already implemented a response to early, weak signals of environmental change by progressively reconfiguring their assets as early as 1999_and, by moving earlier, they may have benefited from favorable market conditions in terms of acquisitions and divestitures. After the shift crystallized on $9 / 11$, the reconfiguration efforts of anticipative adapters remained stable in terms of scope, and they often avoided large-scale operations (e.g., multibillion-dollar acquisitions), refocusing instead on adjusting assets internally by focusing on more targeted, smaller-scale operations (e.g., GEN doubled the number of minor operations post-9/11 while halving the number of major ones). ${ }^{12}$

By contrast, responsive adapters (C2) are defense-focused firms that waited until 2002 to significantly reconfigure their assets, at which time they radically overhauled the structure of their business operations by redistributing many assets across SBUs (e.g., it was not until 2003 that LOC drew from existing SBUs to build a new SBU focused on networked solutions). ${ }^{13}$ And though in 1999, Raytheon CEO D. Burnham declared that the firm "failed to step back and assess how the world was changing" (Business Week, 1999), only in 2002 did top management "shift the strategic profile" of the company (2002 LtS) through a fundamental rethinking of the defense electronics systems offered by the firm, and eventually overcome early inertial pressures.

Both opportunistic (C3) and decisive adapters (C4), which are more diversified into civilian

\footnotetext{
12 The number of operations is not visible in Figure 1.b but it shows that, after adjusting the scope of activities before 2001, the firm kept reinforcing two segments where consolidation was relevant and acquisition targets were available.

13 By contrast, late 1990 s reconfigurations at LOC were due to the integration of assets acquired during the post-Cold War M\&A wave that occurred between 1992 and 1998. For more details, see Figure 1.c.
} 
activities, were late in paying attention to the environmental shift in the defense sector, and opted for a wait-and-see approach to reconfiguring their assets. After 2002, decisive adapters substantially increased both the scope and intensity of their asset reconfigurations by relying more heavily on large-scale divestitures and acquisitions (e.g., beginning in 2003, DRS reconfigured its assets to meet new needs for network-centric solutions, as can be seen on Figure 1.e in 2004-05 and in the figure's accompanying narrative). In contrast, opportunistic adapters primarily leveraged existing assets and redistributed them internally across SBUs, at times reinforcing their existing competences with minor acquisitions. They typically leveraged their competences in civilian businesses and transferred them to those military businesses that showed promising growth opportunities (e.g., HAL leveraged its business-to-government experience in engineering and construction to earn new contracts in military logistics during the so-called "war on terror" in Iraq and Afghanistan; see the reconfiguration of the KBR SBUs in Figure 1.d, and the figure's accompanying narrative).

Finally, our findings reveal a sufficient configuration of causal conditions leading to nonadaptation. Haphazard non-adapters $(\mathrm{CN})$ have low defense dependence, low-intensity, and delayed attention to the shift, together with higher-intensity asset reconfiguration after 9/11 not accompanied by an increase in reconfiguration scope. Thus, inferior attention is necessary for non-adaptation (i.e., all non-adapters have attention scores below 0.5) but not sufficient-other causes are involved. Specifically, for the diversified firms that poorly anticipated the shift, a response based on large-scale acquisitions and divestitures concentrated on a small number of SBUs led to their non-adaptation. This finding underscores the value of a response that is widely distributed across the entire organization (in Table 3, contrast $\mathrm{CN}$ and $\mathrm{C} 4$ ). This result may be explained by the need for firms to align their attention, incentives, and objectives across all SBUs to implement a new strategy effectively.

Finally, it should be noted that, in our results, we find strong evidence, both of equifinality 
(i.e., four distinct paths lead to the same "adaptation" outcome) and of "conjunctural" causation (Ragin, 2008; Crilly et al., 2012: 1433)—that is, some causes produce particular effects only in conjunction with others. This is especially visible in the configurations $\mathrm{C} 4$ and $\mathrm{CN}$ in Table 3; the two configurations share three causal conditions (delayed attention, low-intensity attention, and highintensity reconfiguration) yet lead to opposite outcomes (adaptation for $\mathrm{C} 4$, non-adaptation for $\mathrm{CN}$ ). Thus, the effect produced by these three causes combined depends on yet other causes-here, low defense dependence (for $\mathrm{CN}$ ) and an increase in asset reconfiguration scope after 9/11 (for C4).

Interestingly, Hrebiniak and Joyce's (1985: 341) typology of adaptation isolated a category of adapters consisting of diversified firms operating in "highly regulated industries" with many "legal constraints on the means of conducting business" but "low resource dependency." This depiction aptly describes firms in both $\mathrm{C} 3$ and $\mathrm{CN}$, which have low defense dependence. But this paper's analyses, by further distinguishing between C3 and CN, refine Hrebiniak and Joyce's typology and suggest that adaptation is explained by firms' ability to redistribute assets across SBUs without suddenly increasing their reliance on large-scale acquisitions and divestitures. ${ }^{14}$

\section{CONTRIBUTIONS AND DISCUSSION}

This paper opened with a simple question: How do firms adapt? Our fuzzy-set analyses of U.S. defense firms' responses to $9 / 11$ provide a straightforward answer-firms can adapt in four different ways, by being anticipative, responsive, opportunistic, or decisive.

Our models capture the main variables examined by the two primary theoretical perspectives on adaptation — cognition and capabilities—but our findings suggest that neither dynamic capabilities nor superior cognition must be present for firms to adapt. Indeed, we find superior cognition to be absent from many adaptation events, and that slowing the pace of asset renewal in response to

\footnotetext{
${ }^{14}$ In the two cases depicted in Figure 1, Halliburton (C3) and CSC (CN), the former proved to be more inclined to rethink the configuration of assets associated with defense through the development of KBR Group, by leveraging existing assets rather than relying on extensive external operations.
} 
environmental change can enhance adaptation Thus, this first comparative assessment of the explanatory powers of the cognition and capabilities lenses leads us to qualify and reassess the two literatures. In particular, our findings suggest that cognition and capabilities act sometimes as substitutes and other times as complements.

By cross-fertilizing the cognition and capabilities literatures, our fuzzy-set analyses show the conditions under which a firm is able to adapt when it uses capabilities to reconfigure assets even when its top managers do not display superior attention to environmental cues (i.e., by being decisive, cf. Table 3). We also demonstrate that a firm has no need for early attention to an environmental shift when it has the capability to reconfigure assets swiftly, as illustrated by responsive adapters. While all these findings critically revisit commonly accepted claims in both the cognition and capabilities literatures, they also lay down new foundations for an integrated framework.

Our study also allows us to empirically distinguish between situations wherein managers are not aware of the need for change (i.e., inferior cognition), and situations of strategic non-adaptation, wherein despite awareness of shifting conditions, managers gauge that change is not a priority given the firm's current revenue profile. Put differently, we emphasize situations where it makes sense to deliberately not adapt. Not only does this finding debunk the logical fallacy that equates adaptation with performance but it also qualifies the paper's opening quote by Chakravarthy-yes, "the primary purpose of strategic management is adaptation," but it is not the only purpose, and sometimes strategic action can be underpinned by a decision to not adapt.

Finally, this study provides ample evidence that adaptation and non-adaptation are not symmetrical outcomes-if, say, increased reconfiguration intensity explains adaptation, it does not mean that decreased reconfiguration intensity will explain non-adaptation. This distinction is theoretically important but also methodologically informative; it sets boundaries on the ability of a 
single-case research design to shed light on generalizable mechanisms (e.g., a case study about nonadaptation cannot inform research on adaptive mechanisms).

\section{Toward an Integrated Framework on Firm Adaptation}

Our findings suggest that, when taken separately, the literatures on cognition (Kaplan, 2011) and capabilities (Teece, Pisano, \& Shuen, 1997) are neither necessary nor sufficient to account for firm adaptation in response to environmental shifts. Because our study accounts simultaneously for managerial attention and asset reconfiguration (as well as resource dependence), the resulting taxonomy bridges Chakravarthy (1982) and Hrebiniak and Joyce (1985), thereby providing a more complete yet still parsimonious picture of adaptation and non-adaptation. Furthermore, our study provides additional insights about the two theoretical building blocks of the integrated framework.

First, it adds to prior cognition research. While Eggers and Kaplan (2009) found that managerial attention affects the timing of asset reconfiguration amid technological change, our findings suggest that the timing of firm response is itself closely related to the nature of the response. In particular, delayed attention leads to a delayed response, which is then more likely to rely on large acquisitions and divestitures. At the same time, our results qualify the importance of cognition by showing that firms can adapt despite delayed, low-intensity managerial attention.

The implication is that the role of cognition in adaptive processes may not be as central as was previously believed, and that findings from prior case studies on cognition do not readily generalize (Tripsas \& Gavetti, 2000). At the very least, our study calls for a careful reassessment of prior findings from cognition research since our results show that adaptation can occur without superior cognition at the top managerial level-more specifically, in the language of fsQCA, it is neither a necessary nor a sufficient condition for adaptation. Moreover, by highlighting the importance of resource dependence in driving adaptation, our findings provide a welcome update to arguments advanced thirty years earlier by Hrebiniak \& Joyce (1985). Specifically, we find that non- 
adapters' revenues did not heavily depend on the industry segment undergoing massive change. This suggests an important distinction between situations wherein managers need to implement change but do not realize it (i.e., the cognition argument) and situations wherein they may be aware of shifting conditions yet assess that changing is not a priority, given the firm's current revenue profile (i.e., the resource dependence argument). The latter situation could be described as one of strategic non-adaptation, a phenomenon that has received little scholarly attention in the past.

Second, our study extends research on asset reconfigurations and adaptation. As noted by Teece et al. (1997: 518), "paths [are] the strategic alternatives available to the firm," and our findings distinguish between two broad categories of paths leading to adaptation. On the one hand, responsive, decisive, and opportunistic adapters respond to the environmental shift by substantially increasing the scope of their asset reconfigurations. On the other hand, anticipative adapters rely on lower-intensity reconfigurations and maintain a more stable rate of asset renewal before, during, and after environmental shifts. While the latter trajectory echoes the idea that strategic assets develop as "the cumulative result of adhering to a set of consistent policies over a period of time" (Dierickx \& Cool, 1989: 1506), the former illustrates the possibility of reconfiguring assets rapidly and substantially to respond to an environmental shift—even one that has not been well anticipated.

These two responses are especially interesting to consider from the viewpoint of the literature on dynamic adaptation (Danneels, 2002; Helfat \& Peteraf, 2003; Zahra, Sapienza, \& Davidsson, 2006; Vergne \& Durand, 2011; Zott, 2003). The key tension in this literature comes from the recognition that "capabilities [can be] a source of inertia or adaptation to the environment" (Eggers \& Kaplan, 2013: 295, emphasis added). Indeed, “a company's relentless and successful pursuit of a narrow business strategy $[\ldots]$ may produce coevolutionary lock-in $[\ldots]$, which weakens a company's long-term adaptation" (Burgelman, 1994: 352-353) because "coevolutionary lock-in exacerbates tendencies toward structural inertia” (p. 355). This tension is evident when one compares anticipative 
adapters, who manage to adapt by remaining relatively inert, with the responsive, decisive, and opportunistic adapters. For anticipative adapters, the earlier, sustained, and stable commitment to a strategic path enhances adaptation—an observation echoing Eccles, Nohria, and Berkley's (1992) claim that quick renewal can damage identity, whereas the preferred route is one of "robust action" that maintains long-term flexibility and achieves smaller but clearer outcomes (in this case, many minor asset reconfigurations, as opposed to a few multibillion-dollar acquisitions).

Interestingly, anticipative adapters stand out in terms of attention timing (in Table 3, they are the only firms for which this causal condition is present). Consequently, whether the capabilities used to reconfigure assets lead to damaging inertia or to beneficial adaptation could be a matter of when these capabilities are exercised (Zott, 2003). This perspective points to cognition displaying its most significant effects, not by itself, but in interaction with specific capabilities at specific points in time.

This study also paves the way for an integrative research agenda on adaptation by providing new methodological insights. First, we identified seven issues in past adaptation research for which we offer easily replicable fixes (see Table 1). Second, our mixed-methods approach based on a combination of interview, archival, and survey data allowed us to design robust measures of adaptation and its antecedents. Last but not least, analyzing these rich longitudinal data with fsQCA enabled a deeper investigation of the complex causality underlying adaptation and its (asymmetrical) outcome, namely non-adaptation.

\section{Revisiting an Old Question: Dynamic Capabilities, What Are They?}

Although we do not directly observe dynamic capabilities (DC) in this study, our focus on managerial attention, asset reconfiguration, and adaptation makes some of our findings interpretable through the lens of DC research (Eisenhardt \& Martin, 2000; Helfat et al., 2007). First, asset reconfigurations, one could argue, are the vehicles through which we see DC in action. Second, scholars have claimed that LtS have become "a legitimated measure of managerial cognition" 
(Kaplan, 2011: 679), and that "managerial cognition can be seen as a dynamic managerial capability" (Eggers \& Kaplan, 2013: 324). Thus, accordingly, our measures of attention intensity and timing, which closely follow guidelines established in prior research, could be said to capture a dynamic managerial capability (Adner \& Helfat, 2003). Using that lens, our findings would show that this dynamic managerial capability is neither necessary nor sufficient for adaptation.

An alternative approach conceives of DC as a comprehensive repertoire of actions, implying that cognition should not be examined in isolation (Danneels, 2010; Kor \& Mesko, 2013). If indeed DC must consist of several elements, such as the "sensing-seizing-reconfiguring" tripod (Teece, 2007), then one could reasonably argue that our cognition variables capture the first leg of the tripod, "sensing the environment" (Pavlou \& El Sawy, 2011: 239), and that our asset reconfiguration variables provide a good proxy of the last leg, "reconfiguring assets and structures to maintain competitiveness" (Hodgkinson \& Healey, 2011: 1501). In this context, this study would demonstrate that adaptation to shifting conditions can occur either without superior "sensing" (C3 and C4 in Table 3), or without increasing the pace of "reconfiguring" (C1). Thus, if one believes that both superior sensing and more intense asset reconfigurations are required for DC, our findings imply that, most of the time, adaptation is achieved without exercising DC. ${ }^{15}$

So, in response to perhaps the oldest question in the DC literature stream-"dynamic capabilities: what are they?” (Eisenhardt \& Martin, 2000)—our paper can offer the following: DC is one among several non-necessary, sufficient conditions leading to adaptation, understood as "congruence with the changing business environment" (Teece et al., 1997: 515). Taken together, these considerations recast the adaptation debate within the broader legacy of our field, leave us with

\footnotetext{
15 Only firms in C2, which represent 30\% of the adaptations in our study, display superior sensing and, at the same time, increase substantially the pace of asset reconfigurations after 9/11. If we broaden the definition of DC to include capability exercise by anticipation (as in C1), and not just in response to a changing environment, then $60 \%$ of adaptations could potentially illustrate instances of the exercise of DC. Some may be tempted to broaden the definition of DC enough so as to cover all four paths identified in this study, but then, how can we distinguish between DC and its outcome, namely, enhanced congruence with the environment (Arend \& Bromiley, 2009)? More empirical research relying on causal models is needed to disentangle these various issues.
} 
a qualified view of DC's empirical scope-and a call for more research integrating a variety of perspectives (Peteraf, Di Stefano \& Verona, 2013; Vergne \& Durand, 2011) and methods to investigate causal relationships. We are hopeful that our study has taken a step in the right direction.

\section{Boundary Conditions and Future Research Directions}

Like every industry, defense has its specificities (Baum \& McGahan, 2013; Depeyre \& Dumez, 2008; Durand \& Vergne, 2015). The sector is research- and technology-intensive-new product development can take years - and is dominated by a small number of customers (i.e., governments and their national defense forces) who publish public tenders for competitors to consider (Vergne, 2012). Given the purpose of our study, the defense industry's monopsonistic tendency represents a convenient feature, since it means that U.S. defense firms simply cannot ignore Pentagon demands (thus, differences in cognition patterns observed across firms likely reflect different underlying capabilities, not different levels of interest). Similar competitive dynamics may be found in other R\&D-intensive industries (e.g., in the medical devices and pharmaceutical industries) and in other business-to-government industries (e.g., energy, mining, public construction), where most of our findings would likely generalize. However, in "high-velocity" industries (Nadkarni \& Narayanan, 2007), such as the smartphone industry, where entry barriers are lower, new products are launched every three months, and the customer base is very fragmented, the evolutionary dynamics may differ. For instance, co-evolution between competitors, retailers, and users may drive most high-velocity industries' changes over short time windows, and the environment may be devoid of any discrete, inescapable exogenous changes to which firms must respond.

The firms in our sample are also diverse in their focus. Some are clear defense specialists (e.g., DRS), others are balanced diversifiers spanning related industries (e.g., commercial aircraft and military aircraft for BOE), and yet others are conglomerates holding unrelated businesses in their portfolio (e.g., UNI). Some of our configurations lump these different firms together because of 
their similar responses to $9 / 11$ (e.g., decisive adapters include both DRS and UNI), but, given this heterogeneity, it would also be interesting to know more about how they differ. At the same time, our findings show that substantial differences in terms of corporate scope do not preclude "specialists" and "generalists" from reacting in similar ways to an exogenous shock-a result that provides an interesting counterpoint to extant discussions grounded in ecological theories of adaptation (e.g., Hsu \& Hannan, 2005).

Two other findings from this study likely generalize to other contexts. First, the fact that adaptation is subject to equifinality does not seem to stem from the specificities of our empirical setting. Multiple paths may lead to adaptation, and no conditions related to managerial attention or asset reconfiguration appear to be a requirement to adapt. On a related note, the idea that superior cognition (i.e., early and intense attention to change) can substitute for asset reconfigurations implemented in response to an environmental shift (i.e., for anticipative adapters) would probably apply to any industry shaken by exogenous change. Second, note that all adapters (except anticipative firms) share an increase in reconfiguration scope following $9 / 11$, while non-adapters are the only firms systematically without that condition. This finding points to the value of reconfiguring assets holistically across the entire organization, which can lead to economies of scope, knowledge sharing, creative thinking, and more generally, prevents the creation of organizational silos.

To illustrate this idea, consider new Microsoft CEO Satya Nadella, who became known for his ability to reorganize assets "across once-siloed divisions" in an effort to reinvent Microsoft's innovation capabilities. According to an analyst who has covered Microsoft for more than a decade (Hempel, 2015), "when he wanted to start a cloud-computing business-which would mean borrowing technology from the search engine Bing- he ran up against Microsoft's powerful SQL server business. Normally the SQL team would have instantly squashed Nadella's initiative [but] 'he won that battle [and] it was a huge political shift."” 
One way to delve deeper into this paper's findings and account thoroughly for firm heterogeneity would be to replicate this study using a larger sample. FsQCA can now easily accommodate larger samples (Fiss, 2011; Misangyi \& Acharya, 2014), which would allow for the inclusion of more causal conditions capturing additional aspects of the process leading to adaptation, such as politics or leadership change (e.g., with 200 firms, fsQCA models could handle between 8 and 10 causal conditions). We believe that the indicators of managerial attention and asset reconfigurations designed in this study are easily replicable in other contexts, and potentially at a much lower cost if the coding process were automated. Alternatively, to deepen our understanding of adaptation using small firm samples, researchers could conduct interviews of top managers at the time an exogenous shock occurs. This approach could shed light, for instance, on how internal power and politics shape managerial attention patterns inside the firm (Garud \& Rappa, 1994), as illustrated by the Microsoft example. In any case, we cannot but advocate for more mixed-methods studies (George, 2014) of adaptation given the dual role played by cognition and capabilities-two phenomena that are best observed and measured using a diversity of data sources and methods.

Going forward, an interesting source of data would be middle managers, who, in past studies, have been identified as drivers of firm adaptation (Burgelman, 2002; Christensen \& Bower, 1996; Eisenmann \& Bower, 2000; Vergne \& Durand, 2011). For example, in his research on the trajectory of Intel, Burgelman found that strategic resources were at times reallocated by middle managers without top management's explicit approval (or even awareness), which led Intel to shift strategy and contributed to its adaptation to new industry conditions (Burgelman, 2002; Burgelman \& Grove, 2007). Thus, the LtS used to capture attention —in fact, the attention of top managerscould be missing a dimension of managerial cognition. Given the nature of the defense industry (Depeyre \& Dumez, 2008; Vergne, 2012), we are confident that, in the present study, no major reallocation of resources happened without top management's approval (i.e., given the cost, duration, 
and government regulation of $\mathrm{R} \& \mathrm{D}$ in the defense sector, middle managers cannot take the initiative to develop new weapons programs without top management team approval). But in industries where resource reallocation without top management approval is a possibility, additional data on middle managerial cognition could shed new light on the relationship between attention and asset reconfiguration. For instance, top managerial attention may be necessary for some but not all forms of asset reconfigurations, and middle managerial attention could be sufficient for certain types of resource reallocation (e.g., perhaps within but not across SBUs).

Another interesting feature of our findings is the distinction between internal and external asset reconfigurations. Both anticipative and opportunistic adapters reconfigured their assets after 9/11 by relying more on resources already available internally, whereas decisive adapters substantially increased their reliance on the external, corporate market to acquire and divest large asset bundles. These two alternative paths seem to correlate with patterns of managerial attention, with lowintensity, delayed attention being associated with external asset reconfiguration (for decisive, but also haphazard firms). This correlation would be consistent with the idea that delayed attention calls for a quicker response, and that a quicker response is more easily achieved by acquiring businesses than by developing new assets internally (Dierickx \& Cool, 1989). Future research could thus examine how cognition variables drive the choice to reconfigure assets externally versus internally.

\section{CONCLUSION}

In the context of U.S. defense firms' responses to $9 / 11$, we found that neither dynamic capabilities nor superior cognition must be present for firms to adapt. Using mixed methods and fuzzy-set qualitative comparative analyses (fsQCA), we identified four types of adapters (anticipative, responsive, opportunistic and decisive), as well as the possibility of strategic (i.e. deliberate) nonadaptation. Besides, we did not identify a single causal condition that all four paths to adaptation have in common-i.e., there is no simple successful "recipe" shared by all adapters. 
These results led us to reassess the cognition and capabilities literatures. Importantly, since both cognition- and capability-level variables play a role (by having to be present or absent) in every configuration leading to adaptation and non-adaptation, our results as well as this study's methodological advances open up exciting avenues for further theoretical integration around the essential issue of organizational adaptation.

\section{REFERENCES}

Abrahamson, E., \& Hambrick, D. C. 1997. Attentional homogeneity in industries: The effect of discretion. Journal of Organizational Behavior, 18: 513-532.

Abrahamson, E., \& Park, C. 1994. Concealment of negative organizational outcomes: An agency theory perspective. Academy of Management Journal, 37: 1302-1334.

Adner, R., \& Helfat, C. E. 2003. Corporate effects and dynamic managerial capabilities. Strategic Management Journal, 24: 1011-1025.

Ambrosini, V., Bowman, C., \& Collier, N. 2009. Dynamic capabilities: An exploration of how firms renew their resource base. British Journal of Management, 20: S9-S24.

Arend, R. J., \& Bromiley, P. 2009. Assessing the dynamic capabilities view: Spare change, everyone? Strategic Organization, 7: 75-90.

Barney, J. 1991. Firm resources and sustained competitive advantage. Journal of Management, 17: 99-120.

Barr, P. S. 1998. Adapting to unfamiliar environmental events: A look at the evolution of interpretation and its role in strategic change. Organization Science, 9: 644-649.

Barr, P. S., Stimpert, J. L., \& Huff, A. S. 1992. Cognitive change, strategic action, and organizational renewal. Strategic Management Journal, 13: 15-36.

Baum, J., McGahan, A. 2013. The reorganization of legitimate violence: The contested terrain of the private military and security industry during the post-Cold War era. Research in Organizational Behavior, 33(1): 3-37.

Bowman, E. H. 1982. Risk seeking by troubled firms. Sloan Management Review, 23(4): 33-42.

Bradley, S., \& Aldrich, H. 2011. Resources, environmental change, and survival: asymmetric paths of young independent and subsidiary organizations. Strategic Management Journal, 509, 486-509.

Burgelman, R. A. 1991. Intraorganizational ecology of strategy making and organizational adaptation: Theory and field research. Organization Science, 2, 239-262.

Burgelman, R. A. 1994. Fading Memories: A Process Theory of Strategic Business Exit in Dynamics Environments. Administrative Science Quarterly, 39, 24-56.

Burgelman, R. A. 2002. Strategy as vector and the inertia of coevolutionary lock-in. Administrative Science Quarterly, 47, 325-357.

Burgelman, R. A., \& Grove, A. S. 2007. Let chaos reign, then rein in chaos-repeatedly: managing strategic dynamics for corporate longevity. Strategic Management Journal, 28, 965-979.

Business Week. 1999. Reality bites at Raytheon. November 15: 78-82.

Capron, L., \& Mitchell, W. 2008. Selection capability: How capability gaps and internal social frictions affect internal and external strategic renewal. Organization Science, 20: 294-312.

Cebrowksi, A. K., \& Garstka, J. H. 1998. Network-centric warfare-Its origin and future. U.S. Naval Institute Proceedings Magazine, 124: 28-35.

Chakravarthy, B. 1982. Adaptation: A promising metaphor for strategic management. Academy of Management Review, 7, 35-44.

Cho, T. S., \& Hambrick, D. C. 2006. Attention as the mediator between top management team characteristics and strategic change: The case of airline deregulation. Organization Science, 17: 453-469. 
Christensen C.M, Bower J.L. 1996. Customer power, strategic investment, and the failure of leading firms. Strategic Management Journal, 17: 197-218.

Clapham, S. E., \& Schwenk, C. R. 1991. Self-serving attributions, managerial cognition, and company performance. Strategic Management Journal, 12: 219-229.

Cool, K. O., \& Schendel, D. E. 1987. Strategic group formation and performance: The case of the U.S. pharmaceutical industry. Management Science, 33: 1102-1124.

Crilly, D., Zollo, M., \& Hansen, M. T. 2012. Faking it or muddling through ? Understanding decoupling in response to stakeholder pressures. Academy of Management Journal, 55: 1429-1449.

Danneels, E. 2002. The dynamics of product innovation and firm competences. Strategic Management Journal, 23: 1095-1121.

Danneels, E. 2010. Trying to become a different type of company: Dynamic capability at Smith Corona. Strategic Management Journal, 32: 1-31.

Defense News. 1998-2007. http://special.defensenews.com/top-100. Last accessed in September 2014.

Denrell, J. 2004. Random Walks and Sustained Competitive Advantage. Management Science, 50, 922-934.

Depeyre, C., \& Dumez, H. 2008. What is a market? A Wittgensteinian exercise. European Management Review, 5: 225-231.

Depeyre, C., \& Dumez, H. 2009. A management perspective on market dynamics: Stabilizing and destabilizing strategies in the US defense industry. European Management Journal, 27: 90-99.

D’Este, P. 2002. The distinctive patterns of capabilities accumulation and inter-firm heterogeneity: the case of the Spanish pharmaceutical industry. Industrial and Corporate Change, 11: 847-874.

Dierickx, I., \& Cool, K. 1989. Asset stock accumulation and sustainability of competitive advantage. Management Science, 35: 1504-1511.

Dombrowski, P., \& Ross, A. L. 2008. The revolution in military affairs, transformation and the defence industry. Security Challenges, 4: 13-38.

Drnevich, P., \& Kriauciunas, A. 2011. Clarifying the conditions and limits of the contributions of ordinary and dynamic capabilities to relative firm performance. Strategic Management Journal, 32: 254-279

Durand, R. 2006. Organizational evolution and strategic management. London: Sage.

Durand, R., \& Vaara, E. 2009. Causation, counterfactuals, and competitive advantage. Strategic Management Journal, 30: 1245-1264.

Durand, R., \& Vergne, JP. 2015. Asset divestment as a response to media attacks in stigmatized industries. Strategic Management Journal, 36(8):1205-23

Duriau, V. J., Reger, R. K., \& Pfarrer, M. D. 2007. A content analysis of the content analysis literature in organization studies: Research themes, data sources, and methodological refinements.

Organizational Research Methods, 10: 5-34.

Easterby-Smith, M., Lyles, M. A., \& Peteraf, M. A. 2009. Dynamic capabilities: Current debates and future directions. British Journal of Management, 20: S1-S8.

Eccles, R. G., Nohria, N., \& Berkley, J. D. 1992. Beyond the hype: Rediscovering the essence of management. Boston: Harvard Business School Press.

Eggers, J. P., \& Kaplan, S. 2009. Cognition and renewal: Comparing CEO and organizational effects on incumbent adaptation to technical change. Organization Science, 20: 461-477.

Eggers, J. P., \& Kaplan, S. 2013. Cognition and capabilities. Academy of Management Annals, 7: 293-338.

Eisenhardt, K. M., \& Martin, J. A. 2000. Dynamic capabilities: What are they? Strategic Management Journal, 21: 1105-1121.

Eisenmann, T. R., \& Bower, J. L. 2000. The entrepreneurial M-form: Strategic integration in global media firms. Organization Science, 11: 348-355.

Fiol, C. M. 1990. Explaining strategic alliance in the chemical industry. In A. S. Huff (Ed.), Mapping strategic thought. 227-249. Chichester, NY: John Wiley \& Sons.

Fiol, C. M. 1995. Corporate communications: Comparing executives' private and public statements. Academy of Management Journal, 38: 522-536.

Fiss, P. C. 2007. A set-theoretic approach to organizational configurations. Academy of Management Journal, 32: 1180-1198. 
Fiss, P. C. 2009. Case studies and the configurational analysis of organizational phenomena. In C. C. Ragin \& D. Byrne (Eds.), Handbook of case study methods: 424-440. London: Sage.

Fiss, P. C. 2011. Building better causal theories: A fuzzy set approach to typologies in organization research. Academy of Management Journal, 54: 393-420.

Garud, R. and Rappa, M. A. 1994. A socio-cognitive model of technology evolution: the case of cochlear implants. Organization Science, 5, 344-62.

George, G. 2014. From the editors. Rethinking management scholarship. Academy of Management Journal, 57, 1-6.

Gould S. J. 2002. The structure of evolutionary theory. Cambridge, MA: Harvard University Press.

Greckhamer, T., Misangyi, V. F., Elms, H., \& Lacey, R. 2007. Using qualitative comparative analysis in strategic management research: An examination of combinations of industry, corporate and businessunit effects. Organizational Research Methods, 11: 695-726

Helfat, C. E. 1994. Evolutionary trajectories in petroleum firm R\&D. Management Science, 40: 1720-1747.

Helfat, C. E., Finkelstein, S., Mitchell, W., Peteraf, M. A., Singh, H., Teece, D. J., \& Winter, S.G. 2007. Dynamic capabilities. Understanding strategic change in organizations. Oxford: Basil Blackwell.

Helfat, C. E., \& Peteraf, M. A. 2003. The dynamic resource-based view: Capability lifecycles. Strategic Management Journal, 24: 997-1010.

Helfat, C. E., \& Winter, S. G. 2011. Untangling dynamic and operational capability: Strategy for the (n)everchanging world. Strategic Management Journal, 32: 1243-1250.

Hempel, J. 2015. Restart: Microsoft in the age of S. Nadella. Wired, accessed 5/22/15, www.wired.com/2015/01/microsoft-nadella

Hodgkinson, G. P., \& Healey, M. P. 2011. Psychological foundations of dynamic capabilities: Reflection in strategic management. Strategic Management Journal, 32: 1500-1516.

Hrebiniak, L., \& Joyce, W. 1985. Organizational adaptation: Strategic choice and environmental determinism. Administrative Science Quarterly, 30: 336-349.

Hsu, G., \& Hannan, M. T. 2005. Identities, genres and organizational forms. Organization Science, 16: 474490.

Jacobides, M. G. 2006. The architecture and design of organizational capabilities. Industrial and Corporate Change, 15: 151-171.

Kaplan, S. 2008. Cognition, capabilities, and incentives: Assessing firm response to the fiber-optic revolution. Academy of Management Journal, 51: 672-695.

Kaplan, S. 2011. Research in cognition and strategy: Reflections on two decades of progress and a look to the future. Journal of Management Studies, 48: 665-695.

Kaplan, S., Murray, F., \& Henderson, R. 2003. Discontinuities and senior management: Assessing the role of recognition in pharmaceutical firm response to biotechnology. Industrial and Corporate Change, 12: 203-233.

Karim, S. 2006. Modularity in organizational structure: the reconfiguration of internally developed and acquired business units. Strategic Management Journal, 27: 799-823.

Karim, S., \& Mitchell, W. 2000. Path-dependent and path-breaking change: Reconfiguring business resources following acquisitions in the U.S. medical sector, 1978-1995. Strategic Management Journal, 21: 1061-1081.

Kiesler, S., \& Sproull, L. 1982. Managerial response to changing environments: Perspectives on problem sensing from social cognition. Administrative Science Quarterly, 27: 548-570.

Kor, Y. Y., \& Mesko, A. 2013. Dynamic managerial capabilities: Configuration and orchestration of top executives' capabilities and the firm's dominant logic. Strategic Management Journal, 34: 233-244.

Laamanen, T., \& Wallin, J. 2009. Cognitive dynamics of capability development paths. Journal of Management Studies, 46, 950-981.

Langley, A. 1999. Strategies for theorizing from process data. Academy of Management Review, 24: 691710.

Lasserre, E. 2009. Fort Bragg. Le Figaro, June 27. Accessed January 14, 2010.

Lawrence, P. R., \& Lorsch, J. W. 1967. Organization and environment: Managing differentiation and 
integration. Boston: Harvard University Press.

Leiblein, M. J. 2011. What do resource- and capability-based theories propose? Journal of Management, 37 : 909-932.

Lewin, A. Y., \& Volberda, H. W. 1999. Prolegomena on coevolution: a framework for research on strategy and new organizational forms. Organization Science, 10, 519-534.

Lockheed Martin. 2003. Letter to shareholders. 2-5.

March, J. G. 2006. Rationality, foolishness, and adaptive intelligence. Strategic Management Journal, 27: 201-206.

Martin, J. A. 2011. Dynamic managerial capabilities and the multibusiness team: The role of episodic teams in executive leadership groups. Organization Science, 22, 118-140. doi:10.1287/orsc.1090.0515

Misangyi, V. F., \& Acharya, A. G. 2014. Substitutes or complements? A configurational examination of corporate governance mechanisms. Academy of Management Journal, 57, 1681-1705.

Moliterno, T., \& Wiersema, M. 2007. Firm performance, rent appropriation, and the strategic resource divestment capability. Strategic Management Journal, 28: 1965-1987.

Nadkarni, S., \& Barr, P. S. 2008. Environmental context, managerial cognition, and strategic action: An integrated view. Strategic Management Journal, 29: 1395-1427.

Nadkarni, S., \& Narayanan, V. K. 2007. The evolution of collective strategy frames in high- and low-velocity industries. Organization Science, 18, 688-710.

Northrop Grumman. 1999. Letter to shareholders. 5-7.

Osborne, D. J., Stubbart, C. I., \& Ramaprasad, A. 2001. Strategic groups and competitive enactment: A study of dynamic relationships between mental models and performance. Strategic Management Journal, 22: 435-454.

Pavlou, P. A., \& El Sawy, O. A. 2011. Understanding the elusive black box of dynamic capabilities. Decision Sciences, 42: 239-273.

Peteraf, M. A., Di Stefano, G., \& Verona, G. 2013. The elephant in the room of dynamic capabilities: Bringing two diverging conversations together. Strategic Management Journal, 34: 1389-1410.

Peteraf, M., \& Reed, R. 2007. Managerial discretion and internal alignment under regulatory constraints and change. Strategic Management Journal, 28, 1089-1112.

Pfeffer, J., \& Salancik, G. R. 1978. The external control of organizations: A resource dependence perspective. New York: Harper \& Row.

Porac, J. F., \& Thomas, H. 1994. Cognitive categorization and subjective rivalry among retailers in a small city. Journal of Applied Psychology, 79, 54-66.

Priem, R.L., \& Butler, J.E. 2001. Tautology in the resource-based view and the implications of externally determined resource value: further comments. Academy of Management Review, 26(1): 57-66.

Prudential Financial Research. 2003. Raytheon Co. company report. 27 February.

Ragin, C. 2008. Redesigning social inquiry: Fuzzy sets and beyond. Chicago: University of Chicago Press.

Ragin, C., \& Davey, S. 2014. fs/QCA [Computer Program]. Version 2.5. Irvine, CA: University of California.

Ragin, C., \& Fiss, P. C. 2009. Net effects analysis versus configurational analysis: An empirical demonstration. In C. C. Ragin (Ed.), Redesigning social inquiry: Set relations in social research: 190-212. Chicago: University of Chicago Press.

Raytheon. 2002. Letter to shareholders. 1-3.

Schilke, O. 2014. On the contingent value of dynamic capabilities for competitive advantage: The nonlinear moderating effect of environmental dynamism. Strategic Management Journal, 35: 179-203.

Schneider, C. Q., \& Wagemann, C. 2012. Set-theoretic methods for the social sciences: A guide to qualitative comparative analysis. New York: Cambridge University Press.

Schwenk C .R. 1984. Competitive simplification processes in strategic decision-making. Strategic Management Journal, 5: 111-128.

SIPRI (Stockholm International Peace Research Institute). 2006. SIPRI yearbook 2006. Armaments, disarmament and international security. Oxford: Oxford University Press.

Taylor, A, \& Jackson, M. 2010. Sixty to Zero: An Inside Look at the Collapse of General Motors-and the Detroit Auto Industry. New Haven: Yale University Press. 
Teece, D. J. 2007. Explicating dynamic capabilities: The nature and microfoundations of (sustainable) enterprise performance. Strategic Management Journal, 28: 1319-1350.

Teece, D. J. 2012. Dynamic capabilities: Routines versus entrepreneurial action. Journal of Management Studies, 49: 1395-1401.

Teece, D. J., Pisano, G., \& Shuen, A. 1997. Dynamic capabilities and strategic management. Strategic Management Journal, 18: 509-533.

Tripsas, M. 1997. Unraveling the process of creative destruction: Complementary assets and incumbent survival in the typesetter industry. Strategic Management Journal, 18: 119-142.

Tripsas, M., \& Gavetti, G. 2000. Capabilities, cognition, and inertia: Evidence from digital imaging. Strategic Management Journal, 21: 1147-1161.

U.S. Department of Defense. 1997. Report of the quadrennial defense review.

U.S. Department of Defense. 2001a. Report of the quadrennial defense review.

U.S. Department of Defense. 2001b. Network centric warfare. Report to Congress.

U.S. Joint Chiefs of Staff. 1996. Joint vision 2010.

Wernerfelt, B. 1984. A resource-based view of the firm. Strategic Management Journal, 5: 171-180.

Winter, S. G. 2003. Understanding dynamic capabilities. Strategic Management Journal, 24: 991-995.

Vergne, JP. 2012. Stigmatized categories and public disapproval of organizations: A mixed methods study of the global arms industry (1996-2007). Academy of Management Journal, 55: 1027-52

Vergne, JP, \& Durand, R. 2011. The path of most persistence: an evolutionary perspective on path dependence and dynamic capabilities, Organization Studies, 32(3): 365-382

Wry, T., Cobb, A., \& Aldrich, H. E. 2013. More than a metaphor: Assessing the historical legacy of resource dependence and its contemporary promise as a theory of environmental complexity. Academy of Management Annals, 7: 439-486.

Zahra, S. A., Sapienza, H. J., \& Davidsson, P. 2006. Entrepreneurship and dynamic capabilities: A review, model and research agenda. Journal of Management Studies, 43: 917-955.

Zott, C. 2003. Dynamic capabilities and the emergence of intraindustry differential firm performance: Insights from a simulation study. Strategic Management Journal, 24: 97-125. 
TABLE 1: Seven Issues in Adaptation Research

\begin{tabular}{|c|c|c|}
\hline & Issue & How our research design addresses it \\
\hline $\begin{array}{l}1 . \\
\text { Functionalist } \\
\text { adaptation } \\
\text { fallacy }\end{array}$ & $\begin{array}{l}\text { "Attribut[ing] a priori to any organizational } \\
\text { alteration a high degree of functionality" (Durand, } \\
\text { 2006: } 24 \text { ), that is, positing ex ante a form of } \\
\text { equivalence between, say, an acquisition made in } \\
\text { response to environmental change, and } \\
\text { adaptation itself. }\end{array}$ & $\begin{array}{l}\text { We conceptualize and measure separately asset } \\
\text { reconfigurations (e.g. acquisitions) and the } \\
\text { "adaptation" outcome. Put differently, in our } \\
\text { research design, an acquisition may or may not } \\
\text { enhance adaptation. }\end{array}$ \\
\hline $\begin{array}{l}2 . \\
\text { Tautological } \\
\text { performance } \\
\text { argument }\end{array}$ & $\begin{array}{l}\text { Expost performance levels do not say much } \\
\text { about past adaptation levels (Priem \& Butler, } \\
\text { 2001). Performance can also be explained by luck } \\
\text { (Denrell, 2004) and a well-adapted firm may be } \\
\text { able to create value but unable to capture it } \\
\text { (Leiblein, 2011), leading to low performance. }\end{array}$ & $\begin{array}{l}\text { We use a new measure of adaptation, based on } \\
\text { a survey of industry experts, which does not } \\
\text { rely on performance indicators (but see the } \\
\text { Appendix 3.C for a discussion of the } \\
\text { correlation between adaptation and } \\
\text { performance). }\end{array}$ \\
\hline $\begin{array}{l}3 . \\
\text { Circular } \\
\text { causality }\end{array}$ & $\begin{array}{l}\text { When firms and their external environment co- } \\
\text { evolve (Lewin \& Volberda, 1999), it is hard to } \\
\text { claim that some firms are adapting to their } \\
\text { external environment since the latter is shaped } \\
\text { endogenously. }\end{array}$ & $\begin{array}{l}\text { In our setting, (most of) the shifting } \\
\text { environmental conditions can be attributed to } \\
\text { an external shock (the } 9 / 11 \text { attacks). The shift } \\
\text { is thus largely exogenous. }\end{array}$ \\
\hline $\begin{array}{l}4 . \\
\text { Asymmetrical } \\
\text { causality }\end{array}$ & $\begin{array}{l}\text { Adaptation and non-adaptation can be caused by } \\
\text { different factors, e.g., Tripsas and Gavetti's (2000) } \\
\text { framework is inferred from Polaroid's failed } \\
\text { response to the shift toward digital imaging-so it } \\
\text { cannot shed light on the successful responses } \\
\text { implemented by Nikon or Canon. }\end{array}$ & $\begin{array}{l}\text { We examine separately the causal conditions } \\
\text { that drive adaptation and non-adaptation. }\end{array}$ \\
\hline $\begin{array}{c}5 . \\
\text { Unobservability }\end{array}$ & $\begin{array}{l}\text { A capability may be present but not exercised, } \\
\text { and thus can remain unobservable (Easterby- } \\
\text { Smith et al., 2009). For instance, a firm wishing to } \\
\text { utilize its acquisition capability to reconfigure its } \\
\text { assets may be unable to do so if there is no } \\
\text { suitable acquisition target. }\end{array}$ & $\begin{array}{l}\text { Our empirics capture only observable, realized } \\
\text { asset reconfigurations (we discuss implications } \\
\text { for the capabilities literature in the concluding } \\
\text { section). }\end{array}$ \\
\hline $\begin{array}{l}6 . \\
\text { Deliberate non- } \\
\text { adaptation }\end{array}$ & $\begin{array}{l}\text { While some portions of a firm's environment may } \\
\text { be changing, management may still decide to } \\
\text { forgo the opportunity and instead focus their } \\
\text { efforts on other priority areas (e.g., industry } \\
\text { segments not requiring adaptation). }\end{array}$ & $\begin{array}{l}\text { Priorities are often set based on relationships } \\
\text { of "resource dependence" (Pfeffer \& Salancik, } \\
\text { 1978). We re-introduce this idea too often } \\
\text { ignored in adaptation research, and model } \\
\text { resource dependence between firms and } \\
\text { industry segments to capture potential } \\
\text { decisions to not adapt. }\end{array}$ \\
\hline $\begin{array}{l}7 . \\
\text { Continuous } \\
\text { change }\end{array}$ & $\begin{array}{l}\text { Many scholars assume that asset reconfigurations } \\
\text { are implemented in response to environmental } \\
\text { change, whereas in fact, firms reconfigure their } \\
\text { assets continuously (e.g., they fire and hire } \\
\text { monthly)-i.e., not always to adjust to } \\
\text { environmental change (Arend \& Bromiley, 2009). }\end{array}$ & $\begin{array}{l}\text { We control for each firm's baseline rate of } \\
\text { asset renewal prior to the environmental shift, } \\
\text { which enables us to more confidently attribute } \\
\text { changes observed after the shift to an actual } \\
\text { response. }\end{array}$ \\
\hline
\end{tabular}


TABLE 2: Case Selection and Calibration

\begin{tabular}{lccccccc}
\hline Firm & Acronym & $\begin{array}{c}\text { Defense } \\
\text { Dependence }\end{array}$ & $\begin{array}{c}\text { Attention } \\
\text { Timing }\end{array}$ & $\begin{array}{c}\text { Attention } \\
\text { Intensity }\end{array}$ & $\begin{array}{c}\text { Reconfig } \\
\text { Scope }\end{array}$ & $\begin{array}{c}\text { Reconfig } \\
\text { Intensity }\end{array}$ & $\begin{array}{c}\text { Firm } \\
\text { Adaptation }\end{array}$ \\
\hline Alliant Techsystems & ATK & 0.79 & 1 & 0.66 & 1 & 0 & 0.6 \\
Boeing & BOE & 0.30 & 0.33 & 0.66 & 0.4 & 0.8 & 0.6 \\
Computer Sciences Corp & CSC & 0.16 & 0 & 0.33 & 0.4 & 1 & 0.4 \\
DRS Technologies & DRS & 0.94 & 0.33 & 0.33 & 1 & 0.6 & 0.6 \\
General Dynamics & GEN & 0.78 & 1 & 1 & 0.4 & 0 & 0.8 \\
Halliburton & HAL & 0.02 & 0 & 0.33 & 0.6 & 0 & 1 \\
Harris & HAR & 0.39 & 0 & 0.33 & 0 & 0.2 & 0.6 \\
Honeywell & HON & 0.12 & 0 & 0 & 0 & 0.6 & 0.2 \\
ITT Industries & ITT & 0.29 & 0 & 0 & 0.2 & 0.4 & 0.6 \\
L3-Communications & LLL & 0.66 & 0.66 & 1 & 0.6 & 0.6 & 0.8 \\
Lockheed Martin & LOC & 0.75 & 0 & 0.66 & 0.8 & 0.2 & 0.8 \\
Northrop Grumman & NOR & 0.68 & 1 & 1 & 0.2 & 0.2 & 0.8 \\
Raytheon & RAY & 0.76 & 0.33 & 0.66 & 0.6 & 0.6 & 0.6 \\
Rockwell International & ROC & 0.22 & 0 & 0.66 & 0.8 & 0.2 & 0.8 \\
Textron & TEX & 0.12 & 0 & 0 & 0 & 0.6 & 0.4 \\
United Technologies & UNI & 0.14 & 0 & 0 & 0.8 & 0.8 & 0.8 \\
URS Corp & URS & 0.15 & 0 & 0.66 & 0.4 & 0.6 & 0.2 \\
\hline
\end{tabular}

TABLE 3: Configurations Sufficient for Adaptation and Non-adaptation

\section{Outcome Adaptation}

(C3)

(C4)

Non-adaptation

\begin{tabular}{|c|c|c|c|c|c|}
\hline Configuration & $\begin{array}{c}\text { (C1) } \\
\text { Anticipative }\end{array}$ & $\begin{array}{c}\text { (C2) } \\
\text { Responsive }\end{array}$ & $\begin{array}{c}\text { (C3) } \\
\text { Opportunistic }\end{array}$ & $\begin{array}{c}\text { (C4) } \\
\text { Decisive }\end{array}$ & $\begin{array}{c}(\mathrm{CN}) \\
\text { Haphazard }\end{array}$ \\
\hline \multicolumn{6}{|l|}{ Contextual cause } \\
\hline Defense Dependence & $\bullet$ & $\bullet$ & . & & . \\
\hline \multicolumn{6}{|l|}{ Cognition-related causes } \\
\hline Attention timing & $\bullet$ & & . & . & . \\
\hline Attention intensity & $\bullet$ & $\bullet$ & & . & . \\
\hline \multicolumn{6}{|l|}{ Capability-related causes } \\
\hline Reconfiguration scope & & $\bullet$ & $\bullet$ & $\bullet$ & . \\
\hline Reconfiguration intensity & . & & . & $\bullet$ & $\bullet$ \\
\hline Cases covered & GEN, NOR, ATK & LLL, RAY, LOC & ROC, HAL & UNI, DRS & HON, TEX, CSC \\
\hline Consistency & 0.98 & 0.99 & 0.94 & 0.96 & 0.99 \\
\hline Raw coverage & 0.31 & 0.40 & 0.29 & 0.31 & 0.61 \\
\hline Unique coverage & 0.08 & 0.08 & 0.11 & 0.11 & 0.61 \\
\hline Overall solution consistency & \multicolumn{4}{|c|}{0.97} & 0.99 \\
\hline Overall solution coverage & \multicolumn{4}{|c|}{0.74} & 0.61 \\
\hline
\end{tabular}

Note. Condition is present $=\bullet$; absent $=\bullet$. Because ATK has equal membership in C1 and C2, the authors made a qualitative assessment regarding the configuration that ATK is most representative of. This assessment is illustrative and does not affect the logical minimization. 
FIGURE 1

\section{Legend of Visual Maps}

The level of analysis is the SBU, as reported in financial statements. We also show "non-reporting" SBUs (dotted lines) and groups of SBUs mentioned by some firms. We coded the following asset reconfigurations at the SBU level: mergers, acquisitions, and divestitures; integration of external assets into existing SBUs; addition of new SBUs (via internal development, acquisition, or recombination); deletion of existing SBUs (via divestiture or dissolution, with a potential redeployment of assets across the firm); asset recombination; transfer of businesses from one SBU to another; and relabeling (see Karim, 2006).

The different types of reconfigurations are reported as follows:

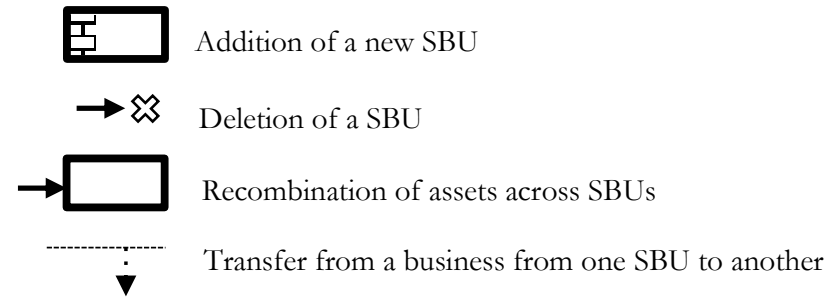

The acquisitions/mergers and divestitures are reported as follows:

4 When a SBU is mainly reinforced via acquisitions (minor vs. major)

- When a SBU is mainly downsized via divestitures (minor vs. major)

= When a SBU has as many acquisitions as divestitures

\section{1.a. A Haphazard (Non)Adapter: Computer Sciences Corp (CSC) - Membership in CN = 0.6}

$$
\text { Attention timing }=0 \mid \text { Attention intensity }=0.33 \mid \text { Reconfiguration scope }=0.4 \mid \bullet \text { Reconfiguration intensity }=1
$$

CSC provides IT outsourcing services to large companies, some of which in the defense and security arena. Despite the dominance of commercial business in the firm's portfolio and a low top managerial attention to the defense environment, the firm took advantage of the market growth over the period, especially after 2003, by acquiring DynCorp (for \$914 million) in the field of homeland security. However, CSC has remained focused on IT services and spun off DynCorp assets related to military equipment and training services. At some point, there were even talks about selling CSC's federal businesses (e.g. in 2005, to Lockheed Martin, which wanted to reinforce its IT capabilities) but CSC did not go through with the plan.

\section{MANAGERIAL ATTENTION TO THE ENVIRONMENTAL SHIFT}

"Demand for CSC's global information security services is strong and growing. We are now providing comprehensive and integrated security services to commercial and government clients around the world. And by building on the solid foundation of providing information security to the U.S. intelligence community, CSC is positioned to lead in the emerging homeland security field." (2002 LTS)

"We also reaffirmed CSC's position as an industry leader in the fight against cyberterrorism and created a federal sector division to meet growing Homeland Security needs." (2003 LTS)
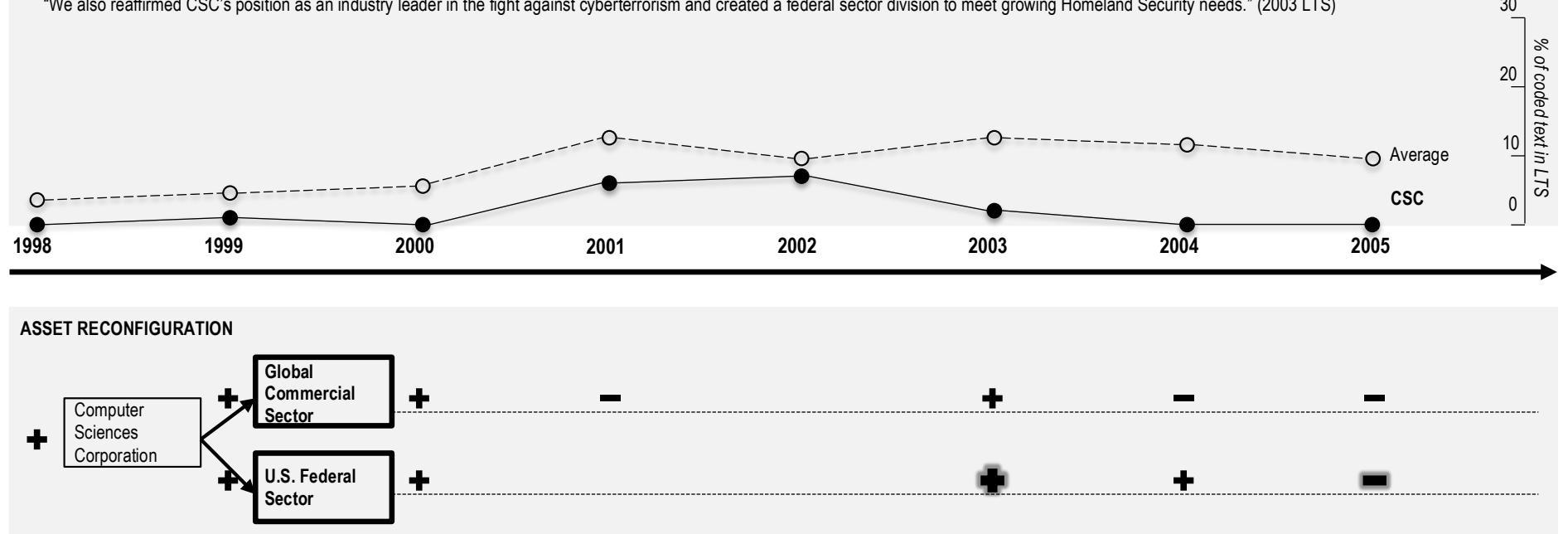


\section{1.b. An Anticipative Adapter: General Dynamics (GEN) - Membership score in C1 = 0.78}

- Attention timing $=1 \mid \bullet$ Attention intensity $=1 \mid$ e Reconfiguration scope $=0.4 \mid$ Reconfiguration intensity $=0$

After releasing major lines of business after the Cold War (e.g., military aircraft and space systems), from 1998, GEN started to build a new division around IT systems. This line was first intended to support GEN's naval and ground platforms, but it became, through a stream of acquisitions and organic growth, a stand-alone SBU with its own market. GEN also returned to commercial business with its acquisition of Gulfstream Aerospace in 1999. It is striking that GEN progressively adapted to the shift without any major overhaul of its SBUs — a very distinctive trajectory compared to close peers such as Boeing, Lockheed Martin or Raytheon.

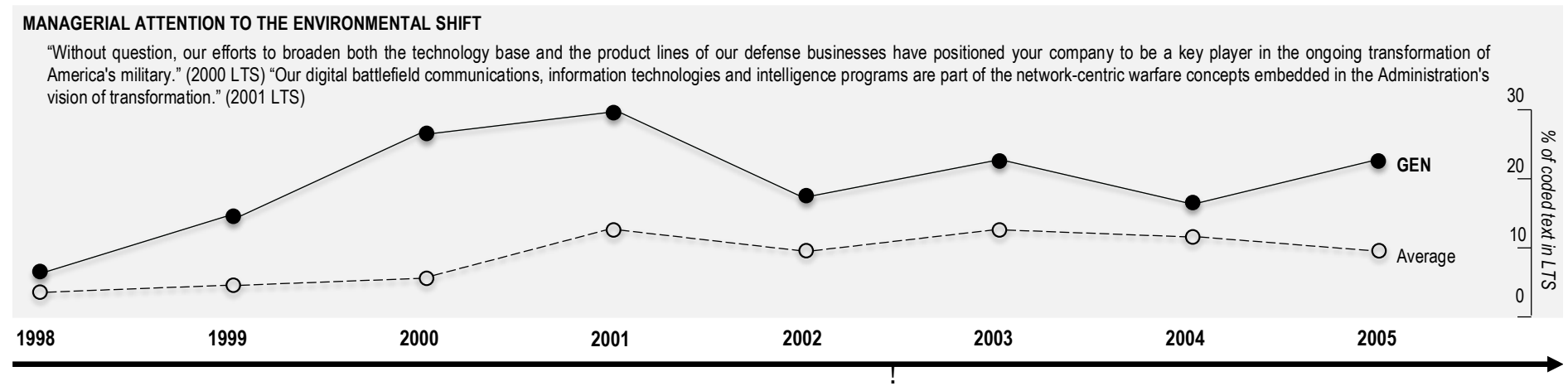

\section{ASSET RECONFIGURATION}

Marine Systems
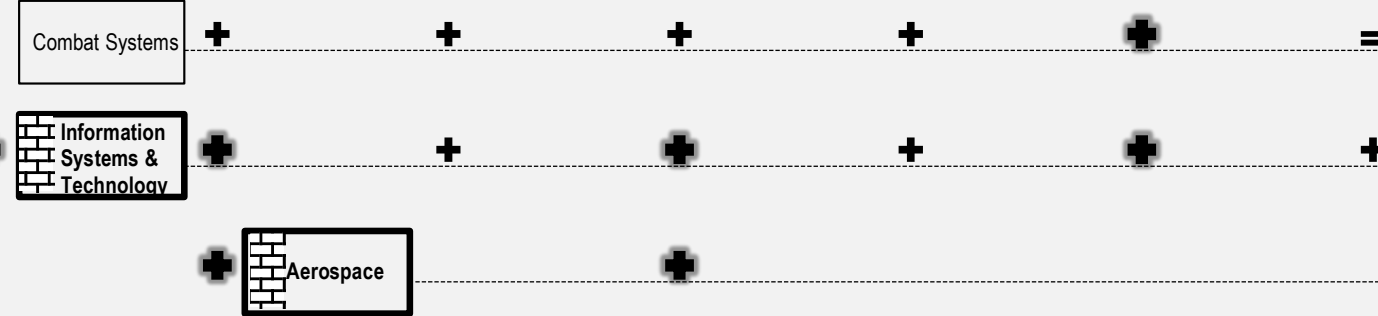

Other 


\title{
1.c. A Responsive Adapter: Lockheed Martin (LOC) - Membership score in C2 = 0.66
}

\author{
Attention timing $=0 \mid \bullet$ Attention intensity $=0.66 \mid \bullet$ Reconfiguration scope $=0.8 \mid$ Reconfiguration intensity $=0.2$
}

In 2003, LOC was the last of the "Big Five" U.S. defense firms to reconfigure its assets in response to the shift. Previously, in 1999, the firm had faced a post-Cold War consolidation crisis, which it attempted to fix by reconfiguring its assets. After an aborted attempt to enter the civilian space communications segment, LOC won the Joint Strike Fighter contract in 2001. This contract put LOC back on track, though not at the core of networkcentric considerations but in a "traditional" (though innovative) segment. Network-centric systems became a visible concern for LOC management only in 2003 when a new SBU, named "Integrated Systems and Solutions", was created to lead the development of network-centric solutions. However, this new organizational structure proved very instable and assets from the new SBU were redistributed again in 2007 across other SBUs (e.g. Technical Services).

\section{MANAGERIAL ATTENTION TO THE ENVIRONMENTAL SHIFT}

"By creating a new business area, Integrated Systems \& Solutions, we are leveraging technical expertise across the breadth of Lockheed Martin to address our customers' requirements for highly integrated, networked solutions. (...) As part of this effort, we are creating the Global Vision Network to enable collaboration among customers and Lockheed Martin. The central node of this highbandwidth engineering network is the Global Vision Integration Center in Suffolk, Virginia, which will lead our development, simulation and analysis of network-centric solutions for the Department of 30 Defense and other national security customers." (2003 LTS)
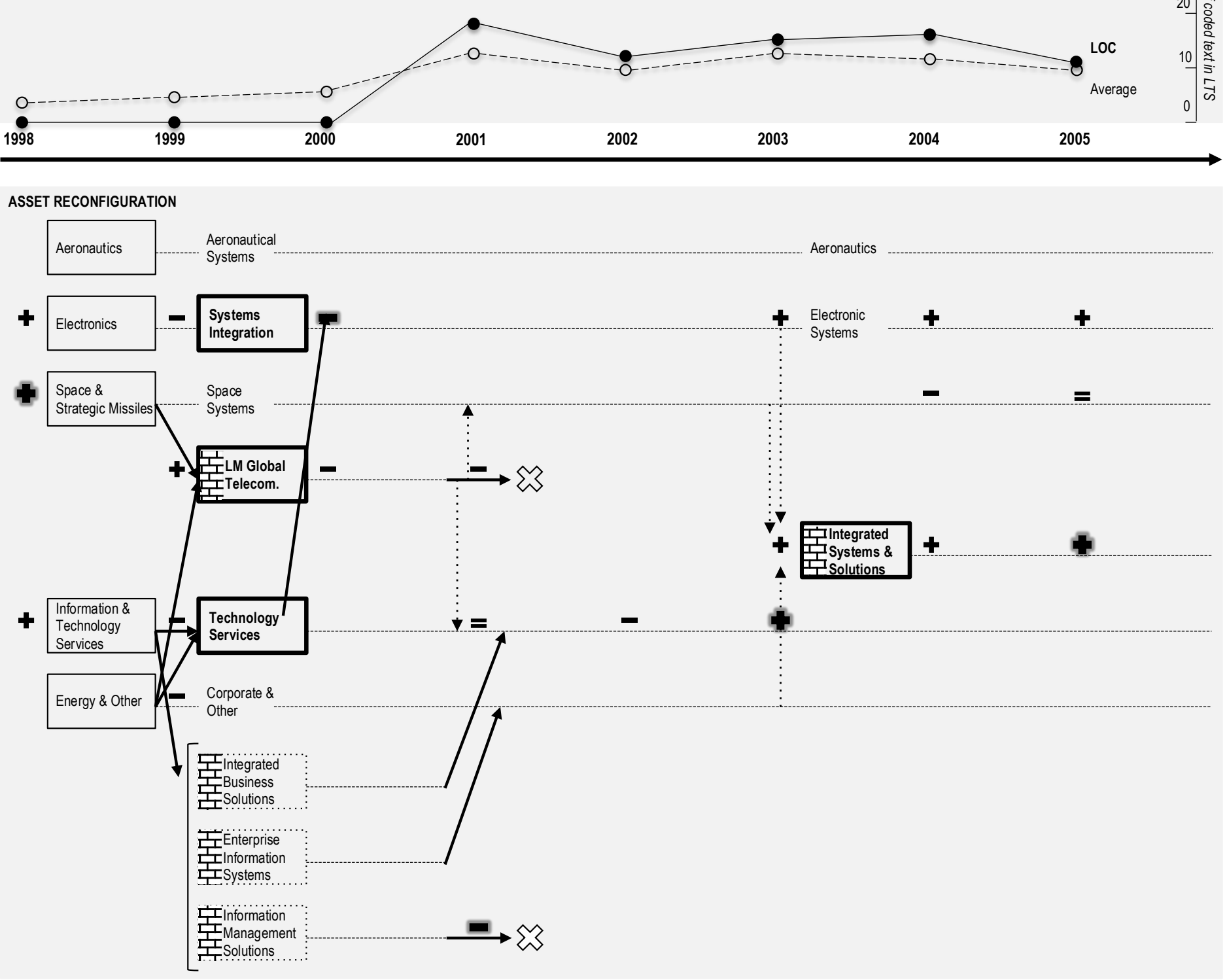


\title{
1.d. An Opportunistic Adapter: Halliburton (HAL) - Membership in C3 = 0.6
}

\author{
Attention timing $=0 \mid$ Attention intensity $=0.33 \mid \bullet$ Reconfiguration scope $=0.6 \mid$ Reconfiguration intensity $=0$
}

After 9/11, HAL seized new opportunities in the booming defense market by leveraging its government experience and network in engineering and construction to earn new contracts in military logistics during the so-called "war on terror" in Iraq and Afghanistan. The corresponding SBU comes from the engineering assets of The M.V. Kellogg Co., acquired in 1998, and the construction assets of Brown \& Root, acquired in 1962. In 2004, the SBU was renamed KBR Group, to be later spun off from HAL in 2007.

\section{MANAGERIAL ATTENTION TO THE ENVIRONMENTAL SHIFT}

"Our industry will always be affected by world events and economics. None of our technologies will change that, and none of them are short-term solutions. They require heavy investment, and they demand that we change the way we think and work. We must pursue the technologies that are best for our Company and our industry tomorrow, next year and for the next generation." (2001 LTS)

"Looking back, 2001 gave rise to a new and frightening world with fear of terrorism, the war in Afghanistan, a global recession and growing geopolitical instability. That atmosphere has persisted, making 30 many companies hesitant to increase their investments because of concerns of what might happen in the future." (2002 LTS)
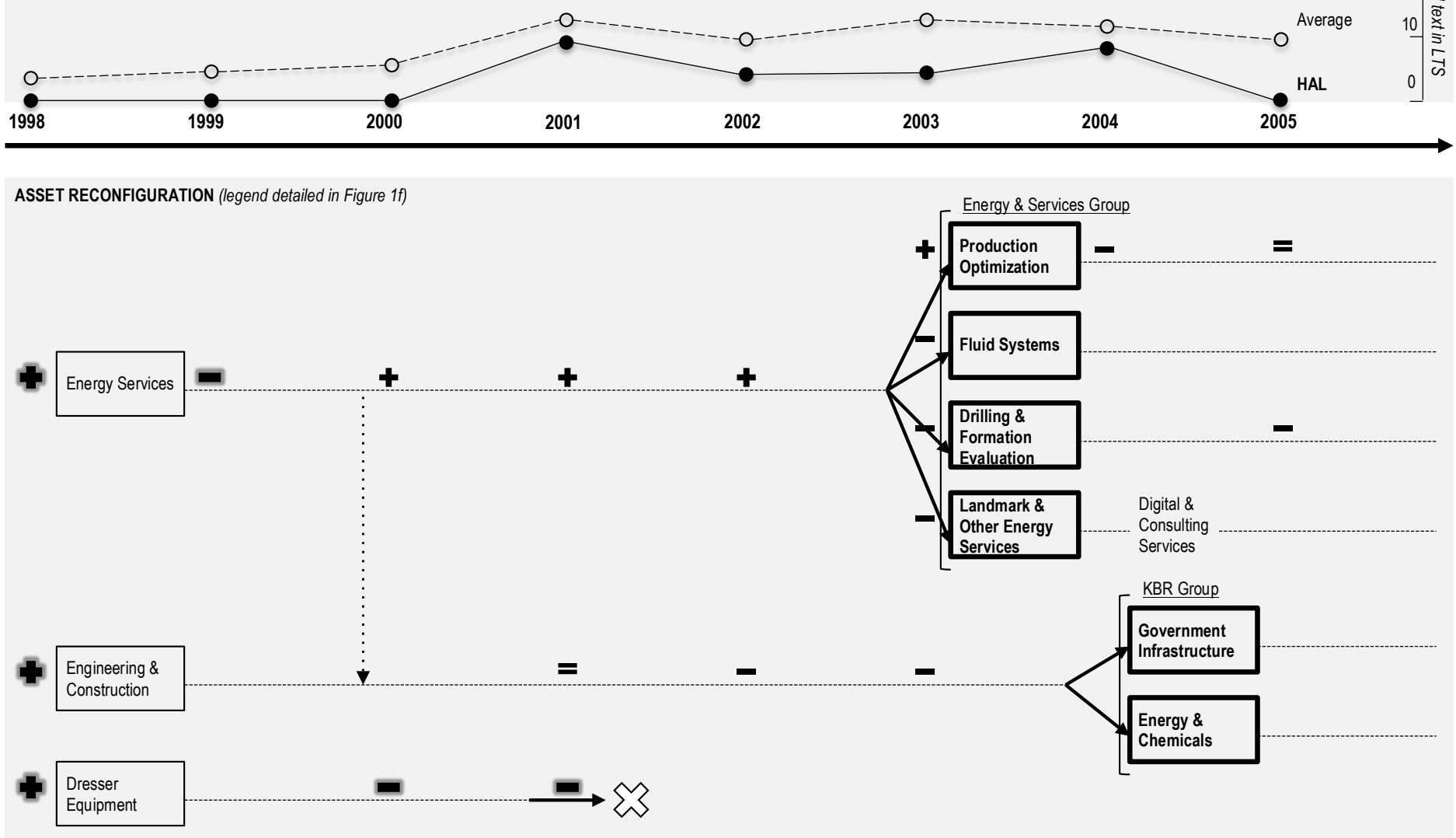


\title{
1.e. A Decisive Adapter: DRS Technologies (DRS) - Membership in C4 = 0.6
}

\author{
Attention timing $=0.33 \mid$ Attention intensity $=0.33 \mid \bullet$ Reconfiguration scope $=1 \mid \bullet$ Reconfiguration intensity $=0.6$
}

DRS is the firm most dependent on the defense market in our sample. Specializing in electronic warfare, DRS managed to substantially increase its defense revenues over the period but much of the transformation effort happened post- $9 / 11$. Only in 2004 did the company reconfigure its portfolio to reflect the evolution of military needs. The three SBUs reconfigured in 2004 and 2005 are typical of the redefinition of military requirements not in terms of products (or sub-systems) but in terms of needs, such as the need for C4ISR capabilities (Command, Control, Communications, Computers, Intelligence, Surveillance and Reconnaissance) and support services. In 2008, DRS Technologies was acquired by Finmeccanica for $\$ 5.2$ billion and thereafter gained access to larger-scale projects.

\section{MANAGERIAL ATTENTION TO THE ENVIRONMENTAL SHIFT}

"As we grow, we are building greater strength to capture an increasingly important role in supplying systems that advance our military customers' transformation initiatives." (2003 LTS)

"DRS's technologies, products and services transcend specific platforms and have broad application across a spectrum of military initiatives associated with both the transformation and recapitalization of military assets. Closely aligned with our customers' objectives for end-to-end, modular system solutions, we are continuing our support of the Current Force as a leading supplier of C4ISR systems for 30 military backfit and modernization programs, as well as our support of the Future Force." (2005 LTS)
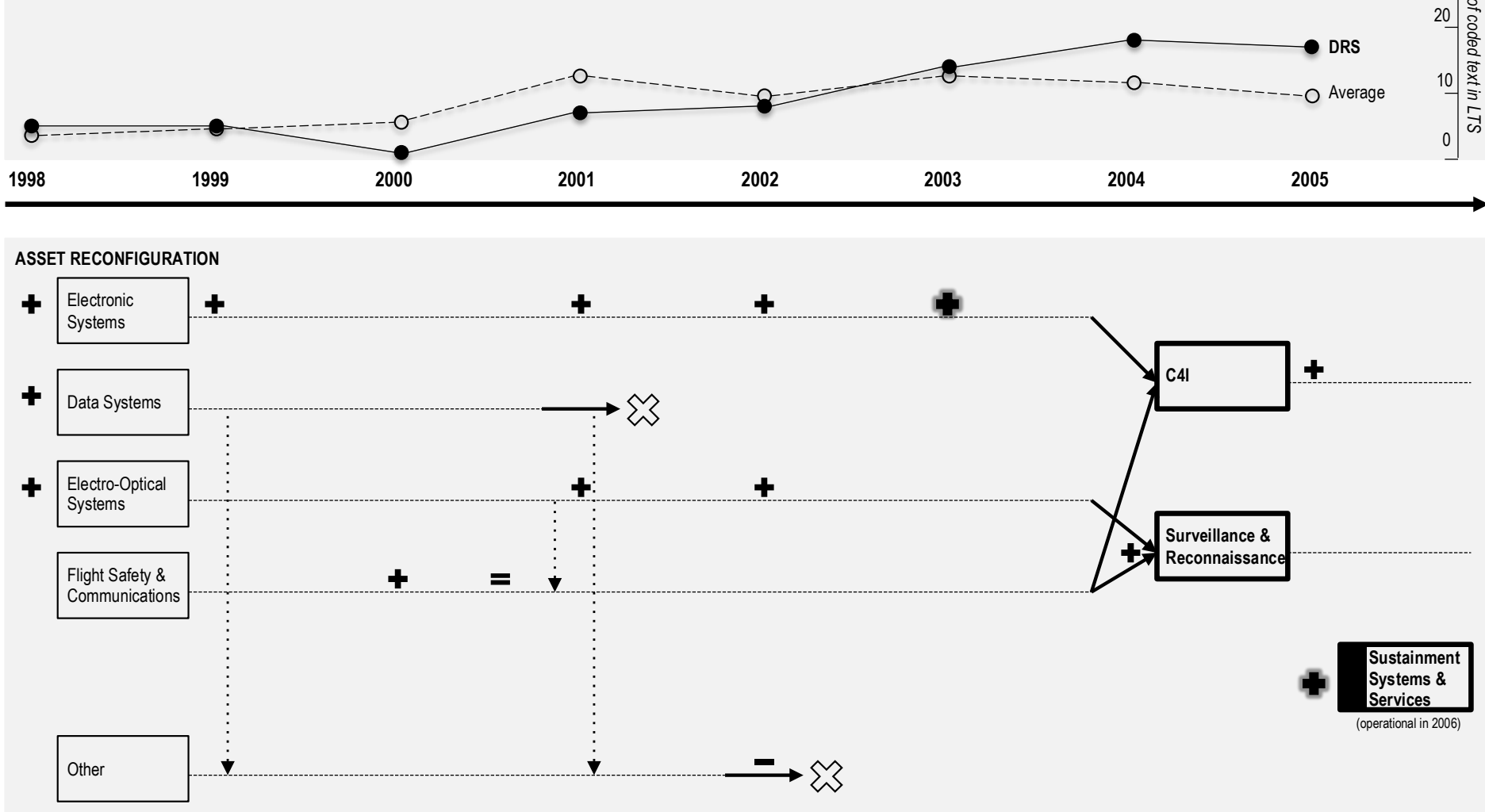


\section{APPENDIX: Methodology}

\section{1/ Calibration of Managerial Attention Using Letters to Shareholders (LtS)}

To calibrate attention timing and attention intensity, we distinguished between defense specialists (defense sales $>65 \%$ of sales) and technology firms diversified in defense (defense sales $<40 \%$ of sales) since firms with low reliance on defense sales are unlikely to pay as much attention to a defense-specific environmental shift. Then, for each group of firms, attention timing was calibrated using the following anchors: 0 when the firm does not pay any attention to shifting environmental conditions prior to $9 / 11 ; 0.33$ when the firm pays some attention to shifting environmental conditions prior to $9 / 11$, but much less so than over the period 2002 to 2005; 0.66 when the firm pays significant attention to shifting environmental conditions prior to $9 / 11$ and maintains that level throughout the entire period; and 1 when most of the firm's attention to external events is focused on the shifting environmental conditions prior to $9 / 11$, and remains focused until 2005. Attention intensity was obtained from a calibration of the average proportion of LtS devoted to discussing the shift over the entire period 1998-2005, comparatively between firms. Substantial attention was coded as 1, moderately high levels were coded as 0.66 , low levels were coded as 0.33 , and insignificant levels as 0 . Figure 1 provides qualitative illustrations of set memberships from LtS and displays diagrams that map attention patterns over time.

\section{2/ Calibration of Asset Reconfiguration Indicators}

Aj Data. Sometimes, firms announce asset reconfigurations whose reality is questionable. For instance, certain firms promised major overhauls after 2001, but little actually happened beyond symbolic change, such as including the term "network" in the SBU's new name. To avoid including cases of decoupling between discourse and actions in our reconfiguration indicators, we focused on changes involving asset acquisitions and divestments. In this respect, we follow the best practice described by Karim (2006), who found that acquisitions are the most consistent trigger of internal reconfigurations, and that divestments too often happen amid reconfigurations within and across SBUs. Put simply, asset acquisition and divestment are reliable and consistently available indicators of both internal and external reconfigurations.

A research assistant extracted lists containing all acquisitions and divestments from Mergent Archives and Lexis Nexis. To identify the SBUs affected by each transaction and the transaction's value, we searched through press releases, annual reports, and Thomson One Banker.

B] Reconfiguration scope. To compute reconfiguration scope, we first calculated the yearly proportion of SBUs affected by asset reconfigurations for each firm, then averaged out these proportions for the two periods 1998-2001 and 2002-2005, and calculated the variation since $9 / 11$ by subtracting the two, using data on 275 events affecting reconfiguration scope:

$$
\sum_{n=2002}^{2005} \frac{\text { Number of Reconfigured SBUs }}{n}-\sum_{n=1998}^{2001} \frac{\text { Number of Reconfigured SBUs }}{\text { Total number of SBUs }} / 4
$$

We allotted the 2001 operations that happened after 9/11 toward the 2002-2005 period. To calibrate reconfiguration scope, we gave membership scores above (below) 0.5 for increases (decreases) after 9/11, and we used deviation scores to capture the intensity of the variation (e.g., a score closer to 1 signals a bigger increase).

CJ Reconfiguration intensity. To capture reconfiguration intensity, we distinguished between major and minor reconfigurations by looking at transaction size (proxied by dollar amounts). While collecting data, we noticed two things.

First, when data regarding transaction amounts were missing from media and company sources, we turned to Thomson One Banker and Infobase and found either no additional information or an estimated transaction amount, typically in the range of $\$ 10$ million to $\$ 350$ million. Often, these transactions did not concern entire business units but facilities (e.g., 
warehouses, plants). Second, for amounts over $\$ 500$ million, specialized media typically provided much more detailed information and analysis (e.g., how the operation feeds into the firm's strategy), a signal of the importance of the transaction. Thus, we decided to use $\$ 500$ million as a threshold.

For each firm in each period (1998-2001 and 2002-2005), we coded the number of minor (no or small transaction amount) and major asset reconfigurations ( $>500$ million), and then computed differences $(\Delta$ 's $)$ across periods. Finally, we computed $\Delta$ (major) $-\Delta$ (minor), as detailed below, using data on 485 asset reconfiguration events:

$\frac{\sum_{\mathrm{n}=2002}^{2005} \text { Major reconfs }_{\mathrm{n}}-\sum_{\mathrm{n}=1998}^{2001} \text { Major reconfs }_{\mathrm{n}}}{\sum_{\mathrm{n}=1998}^{2001} \text { Major reconfs }_{\mathrm{n}}}-\frac{\sum_{\mathrm{n}=2002}^{2005} \text { Minor reconfs }_{\mathrm{n}}-\sum_{\mathrm{n}=1998}^{201} \text { Minor reconfs }_{\mathrm{n}}}{\sum_{\mathrm{n}=1998}^{2001} \text { Minor reconfs }_{\mathrm{n}}}$

Positive (negative) values, indicating more (less) reliance on major vs. minor reconfigurations after 9/11, were calibrated above (below) the 0.5 qualitative anchor.

\section{3/ Supplementary fsQCA Analyses}

A] Alternative measure of reconfiguration intensity. To capture in a different way the changes in reconfiguration intensity between the two periods, we constructed an alternative measure that does not solely rely on quantitatively tracking minor and major acquisitions and divestitures, but instead assesses qualitatively the overall stability of firms' trajectories based on the visual maps (five of which are displayed in Figure 1). Calibrated scores above 0.5 indicate more unstable trajectories punctuated by major asset overhauls after $9 / 11$, including those not relying on acquisitions and divestitures (e.g., major redistribution of internal assets across SBUs). Our alternative measure is less systematic and relies on a more subjective assessment of asset reconfigurations, but does take into account more qualitative information. Sufficiency analysis yields a 5-configuration solution. C1 and C3 are identical to the configurations reported in the paper, C2 is very similar (except that the new causal condition is present too), and the fourth causal condition in our reported model is now split in two distinct configurations. Overall, this alternative model is less parsimonious, decreases consistency slightly, but improves coverage (from 0.74 to 0.83 ). Given these observations, we chose to report the more parsimonious model based on the more objective and more easily replicable measure of reconfiguration intensity.

B] Alternative measure of adaptation. We computed an alternative measure of adaptation by searching for U.S. business press articles that spoke positively of the 17 sampled firms' achievements during the period 2002-2005. The two authors trained a research assistant who extracted the articles from the Factiva database. Several filters were used to extract relevant sources: the firm, the sector (defense/aerospace), and key terms such as "9/11," "terrorism," "networkcentric warfare," or "military transformation." Next, the second author coded as 1 each mention evoking increased congruence to the post-9/11 industry conditions (e.g., Firm X's “investment in network-centric warfare capabilities") and as -1 any event evoking decreased congruence (e.g., Firm Y loses a bid for a "transformational contract"). Obviously, larger firms, firms with a popular brand name (e.g., Boeing), and firms selling popular weapon systems (e.g., F-35 aircraft) are more likely to be discussed in the media, and these factors are very difficult to control for. To make the sum of coded events more comparable across firms, we did not count several times a similar event quoted in several press articles. Also, we computed a measure of that count per dollar of defense revenue (we logged firms' defense revenues to account for heterogeneity in firm size). We also excluded an outlier, HAL, whose defense activities at the time were known under three distinct names (Halliburton, Kellogg Brown \& Root, and KBR), thereby severely biasing the newspaper article search. Our final measure of adaptation, based on expert journalist assessment in the business press, has a minimum of 0.13 , a maximum of 6.66 , a mean of 2.6, and a standard deviation of 1.9. We rank-ordered the firms based on this new 
measure and assigned the same calibrated scores as previously (see Table 2), i.e., 0.2 for the two firms with the lowest scores, 0.4 for the next two, and so forth. Finally, we calculated the correlation between that alternative measure and our expert panel measure, and found a score of 0.77 , which reinforced our confidence in the measure.

CJ The adaptation-performance link. While the relationship between adaptation and performance is complex and should be examined thoroughly in a distinct study, we still want to provide some idea of how our measure of adaptation correlates with a measure of performance. We expect a positive correlation (i.e., on average, firms that adapt should end up in a better position to perform), yet a correlation that is not too close to 1 , otherwise it could mean that we did not successfully mitigate the logical fallacies associated with prior adaptation research (e.g., adaptation captured using an $e x$ post performance metric; see Issue 2 in Table 1). To evaluate the correlation between our measure of adaptation and performance, we created a composite indicator that calculates a weighted average of performance in the defense and civilian divisions of each firm:

Firm Performance $=(\%$ Defense Sales $\times$ Defense Revenue Growth $)+(\%$ Civil Sales $\times($ ROA Growth + Market Cap Growth $) / 2)$, wherein Defense Revenue Growth and Market Capitalization Growth are computed as the difference between the average for the period 2002-2005 minus the average for the period 1998-2001. This composite indicator takes into account three dimensions of performance (variations in ROA, in market value, and in defense revenue) and mitigates two issues: $1 /$ the fact that defense firms typically do not report separately their performance metrics for their military and civilian divisions; 2 / the fact that it can take a few years to observe the ROA consequences of a growth in defense sales (e.g., weapons programs can unfold over 5 to 15 years). The correlation between Performance and Adaptation as measured by our expert panel is $0.53(\mathrm{p}=0.02)$. Using different specifications for the performance indicator yielded correlations ranging between 0.50 and 0.65 . The fact that the correlation is positive, significant and yet not too close to 1 is consistent with discussions on the relationship between adaptation and performance (Durand, 2006), and further reinforces our confidence in our adaptation indicator. Note, however, that a fully-fledged examination of the link between adaptation and performance should probably include an analysis of the costs of asset reconfigurations, and not just the benefits. For, say, an acquisition, these costs could include agency costs (e.g., is the CEO merely interested in growing the firm at the expense of the shareholders?), transaction costs (e.g., the "make or buy" decision), operational costs (e.g., to identify and assess potential acquisition targets), integration costs (e.g., post-acquisition restructuring), and opportunity costs (e.g., what is the cost of not seizing that acquisitions opportunity?). Estimating the costs of the 760 asset reconfiguration events documented in this paper is beyond the scope of our study and requires future research. 
JP Vergne (jvergne@ivey.ca) is an assistant professor at Western University's Ivey Business School (Canada). He holds a PhD from HEC Paris. His research focuses on the evolution of socially contested industries, including arms, cryptocurrency, and more generally industries affected by piracy.

Colette Depeyre (colette.depeyre@dauphine.fr) is an assistant professor at PSL, Université ParisDauphine (France). She holds a PhD from the Université Paris Ouest Nanterre / CRG, École polytechnique. Her research focuses on capabilities and market dynamics in the context of complex product systems as well as luxury and fashion products. 